\title{
Risk Factors Associated with Clinical Outcomes in 323 COVID-19 Patients in Wuhan, China
}

Ling $\mathrm{Hu}^{1 *}$, M.D., Ph.D., Shaoqiu Chen ${ }^{2,3^{*}}$, Ph.D., Yuanyuan Fu², Ph.D., Zitong Gao ${ }^{2,3^{*}}$, Ph.D., Hui Long ${ }^{1 *}$, M.D., Hong-wei Ren ${ }^{1 *}$, M.D., Yi Zuo ${ }^{1,2^{*}}$, M.D., Huan Li ${ }^{1}$, M.D., Jie Wang ${ }^{4}$, M.D., Ph.D., Qing-bang Xu' ${ }^{4}$, M.D., Ph.D., Wen-xiong $\mathrm{Yu}^{1}$, M.D., Jia Liu ${ }^{1}$, M.D., Chen Shao ${ }^{1}$, M.D., Jun-jie Hao ${ }^{1}$, M.D., Chuan-zhen Wang ${ }^{1}$, M.D., Yao Ma ${ }^{1}$, M.D., Zhanwei Wang ${ }^{5}$, Ph.D., Richard Yanagihara $^{6}$, M.D., M.P.H., Jian-ming Wang ${ }^{1}$, M.D., Ph.D., Youping Deng ${ }^{2}$, Ph.D.

1.Tianyou Hospital, Affiliated to Wuhan University of Science and Technology, Wuhan, Hubei, China

2. Department of Quantitative Health Sciences, John A. Burns School of Medicine, University of Hawaii at Manoa, Honolulu, HI, USA

3. Molecular Biosciences and Bioengineering Program, College of Tropical Agriculture and Human Resources, University of Hawaii at Manoa, Honolulu, HI, USA

4. Union Hospital, Tongji Medical College, Huazhong University of Science and Technology, Wuhan, Hubei, China

5. Cancer Epidemiology Program, University of Hawaii Cancer Center, University of Hawaii at Manoa, Honolulu, HI, USA

6. Department of Pediatrics, John A. Burns School of Medicine, University of Hawaii at Manoa, Honolulu, HI, USA

*Drs. Hu, Chen, Fu, Gao, Long, Ren and Zuo contributed equally to this work.

Correspondence to:

Dr. Youping Deng, Department of Quantitative Health Sciences, John A. Burns School of Medicine, University of Hawaii at Manoa, 651 Ilalo Street, Honolulu, HI 96813, USA; Tel: +1808-692-1664; Email: dengy@ hawaii.edu

or

Dr. Jian-ming Wang, Tianyou Hospital, Affiliated to Wuhan University of Science and Technology, Wuhan, Hubei 430065, China, Email: dzk613@gmail.com 


\section{ABSTRACT}

\section{Background}

With evidence of sustained transmission in more than 190 countries, coronavirus disease 2019 (COVID-19) has been declared a global pandemic. As such, data are urgently needed about risk factors associated with clinical outcomes.

\section{Methods}

A retrospective chart review of 323 hospitalized patients with COVID-19 in Wuhan was conducted. Patients were classified into three disease severity groups (non-severe, severe, and critical), based on their initial clinical presentation. Clinical outcomes were designated as favorable and unfavorable, based on disease progression and response to treatments. Logistic regression models were performed to identify factors associated with clinical outcomes, and logrank test was conducted for the association with clinical progression.

\section{Results}

Current standard treatments did not show significant improvement on patient outcomes in the study. By univariate logistic regression model, 27 risk factors were significantly associated with clinical outcomes. Further, multivariate regression indicated that age over 65 years, smoking, critical disease status, diabetes, high hypersensitive troponin I $(>0.04 \mathrm{pg} / \mathrm{mL})$, leukocytosis $(>10$ x $\left.10^{9} / \mathrm{L}\right)$ and neutrophilia ( $\left.>75 \times 10^{9} / \mathrm{L}\right)$ predicted unfavorable clinical outcomes. By contrast, the use of hypnotics was significantly associated with favorable outcomes. Survival analysis also confirmed that patients receiving hypnotics had significantly better survival.

\section{Conclusions}

To our knowledge, this is the first indication that hypnotics could be an effective ancillary treatment for COVID-19. We also found that novel risk factors, such as higher hypersensitive 
medRxiv preprint doi: https://doi.org/10.1101/2020.03.25.20037721; this version posted March 30, 2020. The copyright holder for this preprint (which was not certified by peer review) is the author/funder, who has granted medRxiv a license to display the preprint in perpetuity. It is made available under a CC-BY-NC-ND 4.0 International license. Hu et al. 3

troponin I, predicted poor clinical outcomes. Overall, our study provides useful data to guide early clinical decision making to reduce mortality and improve clinical outcomes of COVID-19.

(Funded by the Natural Science Foundation of Hubei Province ZRMS2019000029 and the Top Youth Talent Program in Hubei Province.) 


\section{INTRODUCTION}

Coronavirus disease 2019 (COVID-19) is a potentially lethal respiratory illness caused by a newly identified coronavirus, named SARS coronavirus 2 (SARS-CoV-2), which was first recognized in December 2019 in Wuhan, in Hubei Province, China. ${ }^{1,2}$ The disease has spread rapidly to more than 190 countries, and as of March 24, 2020, 422,915 confirmed cases and 18,915 deaths have been officially reported worldwide. ${ }^{3-7}$ With sustained transmission on six continents, the World Health Organization (WHO) has recently declared COVID-19 as a global pandemic.

Most previous studies of COVID-19 have focused primarily on epidemiological and clinical characteristics. ${ }^{8-12}$ Wang and co-workers compared the clinical features of 138 hospitalized patients with non-severe and severe COVID-19. ${ }^{10}$ Guan and colleagues updated the clinical characteristic and disease severity in 1,099 laboratory-confirmed cases throughout China. ${ }^{12}$ Only a few studies have investigated risk factors and clinical outcomes. ${ }^{13,14}$ So, it is urgent to identify potential novel risk factors and treatments associated with patient-centered outcomes of COVID-19.

In this study, we analyzed the clinical course of 323 hospitalized patients with COVID-19 from January 8 to March 10, 2020, in Wuhan, to identify risk factors associated with clinical outcomes for improving management guidelines.

\section{METHODS}

\section{Study design}

The institutional ethics board of Tianyou Hospital, an affiliate of the Wuhan University of Science and Technology, approved the conduct of this retrospective review. Oral consent was 
obtained from patients and written informed consent was waived. Tianyou Hospital is one of several designated hospitals for the treatment of COVID-19 in Wuhan.

\section{Case definition}

Electronic medical records (EMR) from inpatients with COVID-19 at Tianyou Hospital were studied. Diagnosis complied with the WHO interim guidance ${ }^{15}$ and the guidelines of COVID-19 diagnosis and treatment trial $5^{\text {th }}$ edition, by the National Health Commission of the People's Republic of China. ${ }^{16}$

The COVID-19 diagnosis was based on (1) the exclusion of other known infectious and non-infectious causes of pneumonia; (2) exposure history in Wuhan in the most recent 14 days or contact history with a confirmed patient or disease cluster; and (3) clinical presentation of fever, respiratory symptoms, characteristic chest computer tomography (CT) image and/or leukopenia and lymphopenia.

\section{Data sources}

A total of 323 patients were enrolled from January 8 to February 20, 2020. Real-time reverse transcription polymerase chain reaction (rRT-PCR) was performed on throat swab specimens of all patients. Clinical signs, disease onset, laboratory tests (including rRT-PCR and CT), treatments, co-morbidities, complications, and outcome data were collected from EMR. All raw data were initially assessed by trained physicians. Based on the clinical presentation at the time of admission, patients were categorized into one of three groups: non-severe, severe and critical. Clinical outcomes (favorable or unfavorable) were based on an average observation period of 28 days, with March 10, 2020 as the final follow-up date. 


\section{Clinical classification}

The disease severity groups included the following: non-severe (patients showed fever, respiratory symptoms and CT presentation of pneumonia; severe (patients showed respiratory distress with $R R \geq 30$ breaths/min, oxygen saturation less than $93 \%$, arterial partial pressure of oxygen/oxygen concentration less than $300 \mathrm{mmHg}$ ); critical (patients showed respiratory failure requiring ventilatory support, as well as shock and organ dysfunction requiring intensive care).

\section{Clinical outcomes}

Disease improvement or favorable clinical outcome included full recovery and discharge, progression from critical/severe to non-severe disease status, PCR positive to negative, and/or maintenance of non-severe status. Disease progression or unfavorable clinical outcome included death, progression from non-severe to severe/critical disease status or severe to critical status, and/or maintenance of severe or critical status.

\section{Statistics Analysis}

Chi-square test or Fisher exact test was used for categorical variables measurements. For continuous variables, student T-test or Mann-Whitney test was used. Multiple imputation was conducted to handle missing data. ${ }^{17}$ Odds ratios (ORs) and $95 \%$ confidence intervals (CIs) were calculated using univariate and multivariate logistic regression models. For survival analysis, the survival time was defined as the interval from the date of admission to the date of death or discharge. The association of risk factors with clinical outcome was analyzed using the KaplanMeier method and log-rank test. All analyses were implemented with R software (version 3.6.2) 
or Statistical Analysis System (SAS) software (version 9.4, SAS Institute Inc., Cary, NC). All $P$ values were two-sided, and those $<0.05$ were considered as statistically significant.

\section{RESULTS}

\section{Clinical characteristics}

Of the 323 patients with COVID-19, 186 (57.6\%) were rRT-PCR positive and 137 (42.4\%) patients were rRT-PCR negative but had typical chest CT image, respiratory symptoms and compatible blood test results at the time of admission. At the end of the study, 252 patients had recovered and were discharged, 35 patients had died (overall case fatality rate, 10.8\%), and 36 patients were still hospitalized.

Based on their initial clinical presentation, the 323 patients were classified into the nonsevere (151), severe (146) and critical (26) disease groups (Table 1). There was no gender difference between the three groups. The median age of patients was 61 years (range, 23-91). Patients over 65 years were overrepresented within the severe $(43.2 \%, 63 / 146)$ and critical $(57.7 \%, 15 / 26)$ disease groups.

On admission, fever $(83.9 \%, 271 / 323)$ and cough $(50.8 \%, 164 / 323)$ were the most common symptoms, while dyspnea $(4.3 \%, 14 / 323)$, chest distress $(0.9 \%, 3 / 323)$ and headache $(0.9 \%$, 3/323) were uncommon.

\section{Clinical outcomes}

The average observation period for the 323 patients was 28 days (range, 20-47 days). Favorable outcomes were recorded in 260 patients and unfavorable outcomes in 63 patients. Among the three disease severity groups, $86.8 \%(131 / 151)$ and $84.9 \%(124 / 146)$ of patients in the non- 
severe and severe groups, respectively, had favorable outcomes. By contrast, 80.8\% (21/26) of patients in the critical group had unfavorable outcomes (Figure 1A). Patients older than 65 years showed more unfavorable than favorable outcomes. Patients with diabetes and body mass index (BMI) of $\geq 30$ were more likely to have unfavorable outcomes (Table 1).

Zopiclone, a cyclopyrrolone-class drug for insomnia, was administered at a dose of $1 \mathrm{mg}$ per day to 82 patients $(25.4 \%)$ for the duration of their hospitalization. Overall, favorable outcomes were recorded in 77 of these patients (Table 1). In comparing hypnotics and nonhypnotics use in patients within the three disease groups, favorable clinical outcomes were more prevalent among patients on hypnotics $(94.7 \%$ vs. $88.5 \%$ for non-severe, $95 \%$ vs. $74.6 \%$ for severe, and $66.7 \%$ vs. $13.0 \%$ for critical) $(p<0.05)$ (Figure 1B). And favorable clinical outcomes were associated with the administration of hypnotics among rRT-PCR-positive and rRT-PCRnegative patients in each disease severity group (Figures $1 \mathrm{C}$ and 1D).

\section{CT and laboratory abnormalities}

The radiologic and laboratory test results are summarized in Table 2 (a complete version is available as Supplementary Table S1). CT abnormalities were found in 314 patients. Groundglass opacity (GGO) findings were bilateral in 55.0\% (83/151), 52.1\% (76/146) and 26.9\% (7/26) of patients in the non-severe, severe and critical disease groups, respectively. Multiple bilateral pulmonary consolidations and intralocular interstitial thickening were observed more frequently among patients with unfavorable outcomes $(11.1 \%, 7 / 63)$ than those with favorable outcomes $(0.8 \%, 2 / 260)$. Representative CT images related to clinical outcomes are shown in Figure S1. 
Laboratory findings between patients with favorable and unfavorable outcomes showed differences in leukocyte and neutrophil counts and C-reactive protein, as well as lactate dehydrogenase, creatinine, alanine aminotransferase, aspartate aminotransferase, blood urea nitrogen, glucose, and serum amyloid A, which were all higher among patients with unfavorable outcomes. Lymphopenia also occurred among $83.6 \%$ of patients with unfavorable outcomes, while D-dimer showed no significant differences.

At the time of admission, the initial rRT-PCR was positive in 186 cases and negative in 137. rRT-PCR was positive more often among patients in the critical (84.6\%) and severe (65.1\%) disease groups, than in the non-severe group (45.7\%). Patients whose rRT-PCR were initially negative also had better clinical outcomes, with only $9.5 \%(13 / 137)$ having unfavorable outcomes.

\section{Treatments and complications}

Results related to treatment and complications are shown in Table 3. Oseltamivir $(69.7 \%$, 225/323), ganciclovir $(71.2 \%, 230 / 323)$, and arbidol $(208 / 323,64.4 \%)$ were the three most frequently used antiviral medications. And one or more courses of moxifloxacin, a broadspectrum antibiotic, was administered to $94.1 \%$ (304/323) of patients. Also, 60.7\% (196/323) of patients were given corticosteroid and glucocorticoid, and 95.7\% (309/323) received alternative therapy or traditional Chinese medicine. Kaletra ${ }^{\circledR}$ (lopinavir/ritonavir), an antiretroviral drug for human immunodeficiency virus infection, was more administered to patients in the critical disease group (46.2\%) and in those with unfavorable than favorable outcomes (23.8\% vs 5.0\%). Interferon- $\alpha$ was also given more often to patients with unfavorable than favorable outcomes (9.5\% vs. 6.2\%). Other medications showed no significant differences in clinical outcomes. 
Oxygen therapy via invasive ventilation and non-invasive ventilation was also given more often to patients with unfavorable clinical outcomes. In comparing the outcome of each treatment within the non-severe or severe or critical disease groups, there was no clear improvement (Figure S2).

Of the 63 patients with unfavorable outcomes, complications, such as arrhythmia $(74.6 \%$ vs. $19.6 \%)$, acute lung injury (69.8\% vs. $21.5 \%)$, shock (55.6\% vs. $3.1 \%)$, acute cardiac injury (33.3\% vs. $1.2 \%)$, and acute respiratory distress syndrome (20.6\% vs. $0 \%)$, were significantly more common in patients with favorable outcomes (Table 3).

\section{Risk factors associated with clinical outcomes and survival analysis}

A total of 27 categorical variables were identified in univariate logistic regression analysis, namely: age, smoking, BMI, hypnotics, dyspnea, diabetes, malignancy, cardiovascular and cerebrovascular diseases, serum amyloid A, procalcitonin, hypersensitive troponin I, creatine kinase $\mathrm{CMB}$, lactate dehydrogenase, alanine aminotransferase, aspartate aminotransferase, blood urea nitrogen, creatinine, glucose, leukocyte count, neutrophil count, platelet count, rRT-PCR at diagnosis, clinical status at admission, bilateral GGO, crazy paving sign, diffuse patchy ground glass and air bronchogram, and multiple bilateral pulmonary consolidation and intralobular interstitial thickening (Table S2). Eight variables were demonstrated as independent risk factors based on the multivariate logistic regression model. The results indicated that age (patients over 65 years), smoking, critical disease designation, diabetes, abnormally higher hypersensitive troponin I $(>0.04 \mathrm{pg} / \mathrm{mL})$, leukocyte count $\left(>10 \times 10^{9} / \mathrm{L}\right)$ and neutrophil count $\left(>75 \times 10^{9} / \mathrm{L}\right)$ were significantly associated with unfavorable clinical outcome, and hypnotics showed significant beneficial effects on clinical outcomes $(p<0.001)$ (Figure $2 \mathrm{~A})$. 
Patients in the non-severe group showed significantly better survival compared with those in the severe and critical groups (Figure 2B). Patients given hypnotics showed significant favorable survival compared with the non-hypnotics (Figure 2C), and patients with positive rRTPCR results showed significantly poorer survival compared with those with negative rRT-PCR (Figure 2D).

\section{DISCUSSION}

In contrast to a previous study, ${ }^{12}$ most patients with COVID-19 in the severe group of our series showed favorable clinical outcomes, at approximately the same frequency as in non-severe cases $(84.9 \%$ vs $86.8 \%)$, and survival analysis demonstrated consistently higher survival rates in nonsevere and severe cases than in critical cases. Although previous studies failed to show that smoking was a risk factor for COVID-19,, 14 multivariate analysis in our study demonstrated that smoking was an independent risk factor for unfavorable outcome. Otherwise, we confirmed findings from other studies ${ }^{10,12,13}$ that age over 65 years and leukocytosis with left shift were associated with poorer clinical outcome.

Zopiclone, a commonly prescribed nonbenzodiazepine soporific, was significantly associated with improved clinical outcome. Patients taking hypnotics showed better outcome at the same disease stage than those not taking hypnotics. For patients in the more severe disease groups, the improvement effect was even more pronounced. Also, in analyzing the effect of hypnotics on rRT-PCR-positive and rRT-PCR-negative patients separately, we found hypnotics had more striking effect on the former. Moreover, hypnotics were identified as an independent factor in the risk model that contributed to better clinical outcomes. Also, patients administered hypnotics had a better survival rate. 
Patients usually showed strong anxiety, sleep deficiency and oxygen insufficiency during disease progression, which will lead to the metabolic dysregulation ${ }^{18,19}$ and immune system abnormalities ${ }^{20}$. Better sleep quality and stress reduction could be one partial reason for prescribing hypnotics to COVID-19 patients. Dimitrov et al indicated that sleep can exert some immune-supportive effects and potentially enhance an effective T cell response, and it has high relevant with some specific sleep disorders or impaired sleep, such as depression and chronic stress. $^{21}$

In addition, the superior efficacy of zopiclone may be due to enhanced gamma aminobutyric acid (GABA) signaling. That is, zopiclone can interact with $\mathrm{GABA}_{\mathrm{A}}$, and $\mathrm{GABA}_{\mathrm{A}}$ receptor can magnify responses to GABA. ${ }^{22} \mathrm{GABA}$ signaling promotes autophagy activation, which improves phagosome maturation and promotes host protection against infections. ${ }^{23}$ To our knowledge, the beneficial effect of hypnotics on clinical outcome has not been reported previously in the management of COVID-19 patients.

Up till now, several description studies have mentioned the non-effective function of current medication treatment no matter which stages or outcomes was ${ }^{10,12,24}$, and it was accord with our study analysis. By specifically comparing the standard treatment effect at the same disease status for each treatment (Figure S2), we didn’t see any standard therapy could improve clinical outcome in the study. However, since only about $25 \%$ of patients in our study took hypnotics, we assume that self-healing could be the major reason for the high recovery rate of patients in the non-severe and severe disease groups. That is, COVID-19 is most likely a selflimited disease in the majority of patients.

Both rRT-PCR-confirmed COVID-19 patients and clinically diagnosed patients who were rRT-PCR negative were included in this study. Due to the burgeoning epidemic and high 
exposure situation in Wuhan, the guidelines for COVID-19 diagnosis and treatment indicated that residents of Wuhan with clinical presentations suggestive of COVID-19 (including respiratory symptoms, CT scan results and laboratory tests excluding other infectious causes of pneumonia) could be admitted to hospital irrespective of the rRT-PCR result. Actually, all of the rRT-PCR-negative patients had CT image features compatible with COVID-19. Moreover, the high false-negativity of rRT-PCR (about $20-40 \%)^{25}$ presents a significant burden on health care providers to use their clinical judgment. And chest $\mathrm{CT}$ has a higher sensitivity for diagnosis of COVID-19 than rRT-PCR. ${ }^{25}$

Several underlying reasons including uneven quality from different detection kits, improper collection of throat swab specimens, and low concentration of virus in samples ${ }^{26}$ can lead to the possible results deviation. Therefore, including the rRT-PCR-negative patients was an important measure to control and prevent the spread of COVID-19 in Wuhan. We found that patients in the severe or critical disease groups were more likely to be rRT-PCR positive. Survival analysis also corroborated that rRT-PCR-positive patients showed poorer clinical outcomes.

Since all patients in our study were tested by the same experienced team using the same rRT-PCR protocol, we believe the major reason for the negative rRT-PCR results in our patient series was due to the low concentration of virus in the throat, which may indicate that patients with negative rRT-PCR test might be less likely to infect other people. We found that only a small portion of patients (less than 10\%) with negative rRT-PCR had unfavorable outcomes. In performing follow-up rRT-PCR on patients in the severe disease group with abnormal CT, we found 23 cases whose first test was negative and later tests were positive. We believe the 
inclusion of rRT-PCR-negative patients with clinically compatible presentation of COVID-19 will help guide clinicians in the care of such patients.

Higher BMI ( $\geq 30)$, hyperglycemia and diabetes, and cardiovascular disease were distinct risk factors for unfavorable clinical outcomes. Angiotensin-converting enzyme-2 (ACE2), which serves as a cell-entry receptor for SARS CoV $-2,{ }^{27}$ plays a protective role for both diabetes and cardiovascular diseases. ${ }^{28,29}$ Kuba and colleagues demonstrated that SARS CoV downregulates ACE2 protein, ${ }^{30}$ which could explain why COVID-19 patients with diabetes and cardiovascular disease have worse clinical outcomes.

We found that abnormally high hypersensitive troponin I was an independent predictor for poor clinical outcome. Increased troponin can enhance coagulation activation. ${ }^{31}$ In patients with COVID-19, immune damage to the hematopoietic system, ischemic hypoxia-reperfusion injury, and drugs can cause coagulation disorders. ${ }^{8,31-34}$ We speculate that increased troponin will induce dysfunction of coagulation and thrombus formation with possible pulmonary embolism, which would further aggravate the patient's condition.

There were some limitations in our study. Incomplete laboratory test results in some patient records may have caused deviations in statistical analysis. Except for hypnotics, we found that all treatments were ineffective and many treatments showed unwanted side effects, including liver injury. ${ }^{35-37}$ Although we did not conduct separate analysis for rRT-PCR-positive and rRTPCR-negative patients, our multivariate analysis identified eight independent risk factors, which were independent of the rRT-PCR result.

Although the vast majority of patients recovered, approximately $20 \%$ of our hospitalized patient cohort had unfavorable clinical outcomes. To what extent chronic respiratory insufficiency or other organ system sequelae occur in COVID-19 patients will require careful 
and prolonged follow-up studies. So far, it seems there is no effective standard treatment.

However, we have found that using hypnotics could significantly improve clinical outcome of

COVID-19. We also found that some novel risk factors that could predict patient outcome,

which can help in early decision making for improving treatment outcomes of COVID-19

patients.

\section{ACKNOWLEDGEMENTS}

We thank all of the staff members of the Tianyou Hospital, affiliated to Wuhan University of

Science and Technology (Li Ming Liu, Jing Zhang, Qiong Luo, Guilian Shang, Ting Li, Qiushi

Zhang, Shuan Liu) for their efforts in collecting the information used in this study. 


\section{REFERENCES}

1. Zhu N, Zhang D, Wang W, et al. A Novel Coronavirus from Patients with Pneumonia in China, 2019. N Engl J Med 2020;382:727-33.

2. Li Q, Guan X, Wu P, et al. Early Transmission Dynamics in Wuhan, China, of Novel Coronavirus-Infected Pneumonia. N Engl J Med 2020. Jan 29. doi: 10.1056/NEJMoa2001316. [Epub ahead of print].

3. Johns Hopkins Coronavirus Resource Center. at https://coronavirus.jhu.edu/.)

4. Chan JF-W, Yuan S, Kok K-H, et al. A familial cluster of pneumonia associated with the 2019 novel coronavirus indicating person-to-person transmission: a study of a family cluster. The Lancet 2020;395:514-23.

5. Phan LT, Nguyen TV, Luong QC, et al. Importation and Human-to-Human Transmission of a Novel Coronavirus in Vietnam. N Engl J Med 2020;382:872-4.

6. Rothe C, Schunk M, Sothmann P, et al. Transmission of 2019-nCoV Infection from an Asymptomatic Contact in Germany. N Engl J Med 2020;382:970-1.

7. $\quad \mathrm{Ng}$ OT, Marimuthu K, Chia PY, et al. SARS-CoV-2 Infection among Travelers Returning from Wuhan, China. N Engl J Med 2020 Mar 12. doi: 10.1056/NEJMc2003100. [Epub ahead of print] 8. Huang C, Wang Y, Li X, et al. Clinical features of patients infected with 2019 novel coronavirus in Wuhan, China. The Lancet 2020;395:497-506.

9. Chen N, Zhou M, Dong X, et al. Epidemiological and clinical characteristics of 99 cases of 2019 novel coronavirus pneumonia in Wuhan, China: a descriptive study. The Lancet 2020;395:507-13.

10. Wang D, Hu B, Hu C, et al. Clinical Characteristics of 138 Hospitalized Patients With 2019 Novel Coronavirus-Infected Pneumonia in Wuhan, China. JAMA 2020 Feb 7. doi: 10.1001/jama.2020.1585. [Epub ahead of print].

11. Wu Z, McGoogan JM. Characteristics of and Important Lessons From the Coronavirus Disease 2019 (COVID-19) Outbreak in China: Summary of a Report of 72314 Cases From the Chinese Center for Disease Control and Prevention. JAMA 2020 Feb 24. doi: 10.1001/jama.2020.2648. [Epub ahead of print].

12. Guan WJ, Ni ZY, Hu Y, et al. Clinical Characteristics of Coronavirus Disease 2019 in China. N Engl J Med 2020 Feb 28. doi: 10.1056/NEJMoa2002032. [Epub ahead of print].

13. Yang X, Yu Y, Xu J, et al. Clinical course and outcomes of critically ill patients with SARSCoV-2 pneumonia in Wuhan, China: a single-centered, retrospective, observational study. The Lancet Respiratory Medicine 2020 Feb 24. pii: S2213-2600(20)30079-5. doi: 10.1016/S2213-2600(20)30079-5. [Epub ahead of print]

14. Zhou F, Yu T, Du R, et al. Clinical course and risk factors for mortality of adult inpatients with COVID-19 in Wuhan, China: a retrospective cohort study. The Lancet 2020 Mar 11: https://doi.org/10.1016/\$0140-6736(20)30566-3.

15. Clinical management of severe acute respiratory infection when Novel coronavirus (2019-nCoV) infection is suspected: Interim Guidance. at https://www.who.int/docs/defaultsource/coronaviruse/clinical-management-of-novel-cov.pdf.)

16. Guideline of COVID-19 diagnosis and treatment trial edition 5th. at http://www.gov.cn/zhengce/zhengceku/202002/09/5476407/files/765d1e65b7d1443081053c29ad37fb07.pdf.)

17. Sterne JA, White IR, Carlin JB, et al. Multiple imputation for missing data in epidemiological and clinical research: potential and pitfalls. BMJ 2009;338:b2393.

18. Sharma S, Kavuru M. Sleep and metabolism: an overview. Int J Endocrinol 2010;2010 : 270832. 19. Mirtschink P, Krek W. Hypoxia-driven glycolytic and fructolytic metabolic programs: Pivotal to hypertrophic heart disease. Biochim Biophys Acta 2016;1863:1822-8. 
20. Gamaldo CE, Shaikh AK, McArthur JC. The sleep-immunity relationship. Neurol Clin 2012;30:1313-43.

21. Dimitrov S, Lange T, Gouttefangeas C, et al. Galphas-coupled receptor signaling and sleep regulate integrin activation of human antigen-specific T cells. J Exp Med 2019;216:517-26.

22. Doble A, Canton T, Malgouris C, et al. The mechanism of action of zopiclone. Eur Psychiatry 1995;10 Suppl 3:117s-28s.

23. Kim JK, Kim YS, Lee HM, et al. GABAergic signaling linked to autophagy enhances host protection against intracellular bacterial infections. Nat Commun 2018;9:4184.

24. Cao B, Wang Y, Wen D, et al. A Trial of Lopinavir-Ritonavir in Adults Hospitalized with Severe Covid-19. N Engl J Med 2020 March 18. doi: 10.1056/NEJMoa2001282. [Epub ahead of print].

25. Ai T, Yang Z, Hou H, et al. Correlation of Chest CT and RT-PCR Testing in Coronavirus Disease 2019 (COVID-19) in China: A Report of 1014 Cases. Radiology 2020:200642.

26. Zhang R, Li J. The way to reduce the"false negative results"of 2019 novel coronavirus nucleic acid detection. National Medical journal of China 2020;100.

27. Cao Y, Li L, Feng Z, et al. Comparative genetic analysis of the novel coronavirus (2019-

nCoV/SARS-CoV-2) receptor ACE2 in different populations. Cell Discov 2020;6:11.

28. Batlle D, Jose Soler M, Ye M. ACE2 and diabetes: ACE of ACEs? Diabetes 2010;59:2994-6.

29. Patel VB, Parajuli N, Oudit GY. Role of angiotensin-converting enzyme 2 (ACE2) in diabetic cardiovascular complications. Clin Sci (Lond) 2014;126:471-82.

30. Kuba K, Imai Y, Rao S, et al. A crucial role of angiotensin converting enzyme 2 (ACE2) in SARS coronavirus-induced lung injury. Nat Med 2005;11:875-9.

31. Terres W, Kümmel P, Sudrow A, Reuterb H, Meinertz T, Hamm CW. Enhanced coagulation activation in troponin T-positive unstable angina pectoris. American Heart Journal 1998;135:281-6.

32. Witkowski M, Landmesser U, Rauch U. Tissue factor as a link between inflammation and coagulation. Trends Cardiovasc Med 2016;26:297-303.

33. Lee DU, Je SH, Yoo SJ, et al. Hematological adverse effects and pharmacokinetics of ribavirin in pigs following intramuscular administration. J Vet Pharmacol Ther 2017;40:561-8.

34. Oliver WC. Anticoagulation and coagulation management for ECMO. Semin Cardiothorac Vasc Anesth 2009;13:154-75.

35. Zhang C, Shi L, Wang F-S. Liver injury in COVID-19: management and challenges. The Lancet Gastroenterology \& Hepatology 2020 Mar 4. pii: S2468-1253(20)30057-1. doi: 10.1016/S24681253(20)30057-1. [Epub ahead of print].

36. Fang S, Qi L, Zhou N, Li C. Case report on alimentary tract hemorrhage and liver injury after therapy with oseltamivir: A case report. Medicine (Baltimore) 2018;97:e12497.

37. Terelius Y, Figler RA, Marukian S, et al. Transcriptional profiling suggests that Nevirapine and Ritonavir cause drug induced liver injury through distinct mechanisms in primary human hepatocytes. Chem Biol Interact 2016;255:31-44. 


\begin{tabular}{|c|c|c|c|c|c|c|c|c|}
\hline & \multirow{2}{*}{ All Patients } & \multicolumn{3}{|c|}{ Disease severity group } & \multirow[t]{3}{*}{ p Value } & \multicolumn{2}{|c|}{ Clinical outcome } & \multirow[t]{3}{*}{ p Value } \\
\hline & & Non-severe & Severe & Critical & & Unfavorable & Favorable & \\
\hline & 323 & 151 & 146 & 26 & & 63 & 260 & \\
\hline \multicolumn{9}{|l|}{ Characteristic } \\
\hline $\begin{array}{l}\text { Median Age(years) } \\
\text { (range) }\end{array}$ & $61(23-91)$ & $56(23-89)$ & $64(23-87)$ & $70(44-91)$ & $<0.001$ & $70(38-91)$ & $58(23-89)$ & 0.736 \\
\hline Age group(years) & & & & & $<0.001$ & & & $<0.001$ \\
\hline $20-40$ & $34 / 323(10.5)$ & 21/151(13.9) & $13 / 146(8.9)$ & $0 / 26(0)$ & 0.062 & $1 / 63(1.6)$ & $33 / 260(12.7)$ & 0.006 \\
\hline $41-65$ & $178 / 323(55.1)$ & $97 / 151(64.2)$ & 70/146(47.9) & $11 / 26(42.3)$ & 0.007 & 25/63(39.7) & $153 / 260(58.8)$ & 0.009 \\
\hline$\geq 65$ & $111 / 323(34.4)$ & $33 / 151(21.9)$ & $63 / 146(43.2)$ & $15 / 26(57.7)$ & $<0.001$ & $37 / 63(58.7)$ & $74 / 260(28.5)$ & $<0.001$ \\
\hline Sex & & & & & 0.840 & & & 0.247 \\
\hline Male & $166 / 323(51.4)$ & 75/151(49.7) & 77/146(52.7) & $14 / 26(53.8)$ & 0.840 & $37 / 63(58.7)$ & $129 / 260(49.6)$ & \\
\hline Female & $157 / 323(48.6)$ & 76/151(50.3) & $69 / 146(47.3)$ & $12 / 26(46.2)$ & 0.840 & $26 / 63(41.3)$ & $131 / 260(50.4)$ & \\
\hline \multicolumn{9}{|l|}{ Occupation } \\
\hline Employee & $98 / 323(30.3)$ & $63 / 151(41.7)$ & $34 / 146(23.3)$ & $1 / 26(3.8)$ & $<0.001$ & $8 / 63(12.7)$ & $90 / 260(34.6)$ & 0.001 \\
\hline Self-Employed & $12 / 323(3.7)$ & $5 / 151(3.3)$ & $7 / 146(4.8)$ & $0 / 26(0)$ & 0.666 & $0 / 63(0)$ & $12 / 260(4.6)$ & 0.133 \\
\hline Retired & $144 / 323(44.6)$ & $61 / 151(40.4)$ & $59 / 146(40.4)$ & $24 / 26(92.3)$ & $<0.001$ & $44 / 63(69.8)$ & $100 / 260(38.5)$ & $<0.001$ \\
\hline Unemployed & $69 / 323(21.4)$ & $22 / 151(14.6)$ & $46 / 146(31.5)$ & $1 / 26(3.8)$ & $<0.001$ & 11/63(17.5) & $58 / 260(22.3)$ & 0.502 \\
\hline Medical Staff & $9 / 323(2.8)$ & 7/151(4.6) & $2 / 146(1.4)$ & $0 / 26(0)$ & 0.192 & $1 / 63(1.6)$ & $8 / 260(3.1)$ & 1.000 \\
\hline BMI & & & & & 0.750 & & & 0.017 \\
\hline$<25$ & $229 / 323(70.9)$ & $103 / 130(79.2)$ & $106 / 139(76.3)$ & $20 / 25(80)$ & 0.850 & $44 / 56(78.6)$ & $185 / 238(77.7)$ & 1.000 \\
\hline $25-30$ & $52 / 323(16.1)$ & 22/130(16.9) & 27/139(19.4) & $3 / 25(12)$ & 0.718 & $6 / 56(10.7)$ & $46 / 238(19.3)$ & 0.185 \\
\hline$\geq 30$ & $13 / 323(4)$ & $5 / 130(3.8)$ & $6 / 139(4.3)$ & $2 / 25(8)$ & 0.522 & $6 / 56(10.7)$ & $7 / 238(2.9)$ & 0.029 \\
\hline Onset time-Median(range) & $9(1-60)$ & $8.5(1-30)$ & $10(1-60)$ & $8.5(2-20)$ & 0.093 & $9(1-28)$ & $9(1-60)$ & 0.021 \\
\hline Hypnotics & & & & & $<0.001$ & & & $<0.001$ \\
\hline Yes & $82 / 323(25.4)$ & 19/132(14.4) & $60 / 127(47.2)$ & $3 / 26(11.5)$ & $<0.001$ & $5 / 55(9.1)$ & $77 / 230(33.5)$ & \\
\hline No & $203 / 323(62.8)$ & $113 / 132(85.6)$ & $67 / 127(52.8)$ & $23 / 26(88.5)$ & $<0.001$ & $50 / 55(90.9)$ & $153 / 230(66.5)$ & \\
\hline
\end{tabular}




\section{Temperature $\left({ }^{\circ} \mathrm{C}\right)$}

$\leq 37.00$

37.01-38.00

38.01-39.00

$\geq 39.01$

\section{Smoking history}

Yes

No

Drinking

Yes

No

Signs and symptoms

Fever

Cough

Fever and Cough

Chest distress

Nausea and vomiting

Dyspnea

Shivering

Headache

Chronic medical

illness/coexisting conditions

Cirrhosis

Hypertension

Diabetes

Malignancy

Cerebrovascular disease

COPD'

\begin{tabular}{|c|c|c|c|c|c|c|c|}
\hline 133/323(41.1) & $63 / 150(42)$ & $65 / 146(44.5)$ & $5 / 26(19.2)$ & 0.049 & $26 / 63(41.3)$ & $107 / 259(41.3)$ & 1.000 \\
\hline $105 / 323(32.5)$ & $43 / 150(28.7)$ & $54 / 146(36.9)$ & $8 / 26(30.7)$ & 0.305 & $16 / 63(25.4)$ & $89 / 259(34.4)$ & 0.226 \\
\hline $67 / 323(20.7)$ & $34 / 150(22.7)$ & $24 / 146(16.4)$ & $9 / 26(34.6)$ & 0.081 & $15 / 63(23.8)$ & $52 / 259(20.1)$ & 0.630 \\
\hline \multirow[t]{2}{*}{$17 / 323(5.3)$} & $10 / 150(6.7)$ & $3 / 146(2.1)$ & 4/26(15.4) & 0.011 & $6 / 63(9.5)$ & $11 / 259(4.2)$ & 0.172 \\
\hline & & & & 0.123 & & & 0.045 \\
\hline $38 / 323(11.8)$ & 12/151(7.9) & $22 / 146(15.1)$ & $4 / 26(15.4)$ & 0.123 & $12 / 63(19)$ & $26 / 260(10)$ & \\
\hline \multirow[t]{2}{*}{$285 / 323(88.2)$} & 139/151(92.1) & $124 / 146(84.9)$ & $22 / 26(84.6)$ & 0.123 & $51 / 63(81)$ & $234 / 260(90)$ & \\
\hline & & & & 0.078 & & & 0.816 \\
\hline $36 / 323(11.1)$ & 18/151(11.9) & $12 / 146(8.2)$ & $6 / 26(23.1)$ & 0.078 & $6 / 63(9.5)$ & $30 / 260(11.5)$ & \\
\hline $287 / 323(88.9)$ & 133/151(88.1) & $134 / 146(91.8)$ & $20 / 26(76.9)$ & 0.078 & $57 / 63(90.5)$ & $230 / 260(88.5)$ & \\
\hline 271/323(83.9) & 130/151(86.1) & $121 / 146(82.9)$ & $20 / 26(76.9)$ & 0.452 & $51 / 63(81)$ & $220 / 260(84.6)$ & 0.604 \\
\hline $164 / 323(50.8)$ & 74/151(49) & $77 / 146(52.7)$ & $13 / 26(50)$ & 0.810 & $34 / 63(54)$ & $130 / 260(50)$ & 0.671 \\
\hline $244 / 323(75.5)$ & $100 / 151(66.2)$ & $127 / 146(87)$ & $17 / 26(65.4)$ & $<0.001$ & $46 / 63(73)$ & $198 / 260(76.2)$ & 0.721 \\
\hline $3 / 323(0.9)$ & $0 / 151(0)$ & 2/146(1.4) & $1 / 26(3.8)$ & 0.067 & $2 / 63(3.2)$ & $1 / 260(0.4)$ & 0.098 \\
\hline $1 / 323(0.3)$ & $0 / 151(0)$ & $0 / 146(0)$ & $1 / 26(3.8)$ & 0.080 & $1 / 63(1.6)$ & $0 / 260(0)$ & 0.195 \\
\hline $14 / 323(4.3)$ & $6 / 151(4)$ & $6 / 146(4.1)$ & $2 / 26(7.7)$ & 0.537 & $6 / 63(9.5)$ & $8 / 260(3.1)$ & 0.056 \\
\hline $1 / 323(0.3)$ & $1 / 151(0.7)$ & $0 / 146(0)$ & $0 / 26(0)$ & 1.000 & $0 / 63(0)$ & $1 / 260(0.4)$ & 1.000 \\
\hline $3 / 323(0.9)$ & $3 / 151(2)$ & $0 / 146(0)$ & $0 / 26(0)$ & 0.313 & $0 / 63(0)$ & $3 / 260(1.2)$ & 1.000 \\
\hline $3 / 323(0.9)$ & $3 / 151(2)$ & $0 / 146(0)$ & $0 / 26(0)$ & 0.313 & $0 / 63(0)$ & $3 / 260(1.2)$ & 1.000 \\
\hline $105 / 323(32.5)$ & $39 / 151(25.8)$ & $56 / 146(38.4)$ & $10 / 26(38.5)$ & 0.056 & $27 / 63(42.9)$ & $78 / 260(30)$ & 0.071 \\
\hline 47/323(14.6) & 14/151(9.3) & $22 / 146(15.1)$ & $11 / 26(42.3)$ & $<0.001$ & $19 / 63(30.2)$ & $28 / 260(10.8)$ & $<0.001$ \\
\hline $5 / 323(1.5)$ & $0 / 151(0)$ & $4 / 146(2.7)$ & $1 / 26(3.8)$ & 0.033 & $3 / 63(4.8)$ & $2 / 260(0.8)$ & 0.053 \\
\hline $7 / 323(2.2)$ & 4/151(2.6) & $3 / 146(2.1)$ & $0 / 26(0)$ & 1.000 & $2 / 63(3.2)$ & $5 / 260(1.9)$ & 0.626 \\
\hline $6 / 323(1.9)$ & $0 / 151(0)$ & $5 / 146(3.4)$ & $1 / 26(3.8)$ & 0.033 & $2 / 63(3.2)$ & $4 / 260(1.5)$ & 0.332 \\
\hline
\end{tabular}




\begin{tabular}{|c|c|c|c|c|c|c|c|c|}
\hline Chronic kidney disease & $7 / 323(2.2)$ & $4 / 151(2.6)$ & $3 / 146(2.1)$ & $0 / 26(0)$ & 1.000 & $0 / 63(0)$ & $7 / 260(2.7)$ & 0.353 \\
\hline Chronic liver disease & $5 / 323(1.5)$ & $3 / 151(2)$ & $2 / 146(1.4)$ & $0 / 26(0)$ & 1.000 & $0 / 63(0)$ & $5 / 260(1.9)$ & 0.587 \\
\hline $\begin{array}{l}\text { Cardiovascular and } \\
\text { cerebrovascular diseases }\end{array}$ & $41 / 323(12.7)$ & $8 / 151(5.3)$ & $22 / 146(15.1)$ & $11 / 26(42.3)$ & $<0.001$ & $13 / 63(20.6)$ & $28 / 260(10.8)$ & 0.057 \\
\hline Digestive system disease & $22 / 323(6.8)$ & $8 / 151(5.3)$ & $10 / 146(6.8)$ & $4 / 26(15.4)$ & 0.158 & $7 / 63(11.1)$ & $15 / 260(5.8)$ & 0.218 \\
\hline Endocrine system disease & $15 / 323(4.6)$ & $4 / 151(2.6)$ & $10 / 146(6.8)$ & $1 / 26(3.8)$ & 0.219 & $4 / 63(6.3)$ & $11 / 260(4.2)$ & 0.504 \\
\hline Nervous system disease & $10 / 323(3.1)$ & $5 / 151(3.3)$ & $3 / 146(2.1)$ & $2 / 26(7.7)$ & 0.258 & $4 / 63(6.3)$ & $6 / 260(2.3)$ & 0.109 \\
\hline Respiratory system disease & $29 / 323(9)$ & $8 / 151(5.3)$ & $15 / 146(10.3)$ & $6 / 26(23.1)$ & 0.010 & $9 / 63(14.3)$ & $20 / 260(7.7)$ & 0.162 \\
\hline
\end{tabular}

*The clinical outcome was categorized into unfavorable and favorable. Unfavorable; patients died, or the condition was getting worse. Favorable; patients discharged, or condition improved.

+COPD; Chronic obstructive pulmonary disease 


\begin{tabular}{|c|c|c|c|c|c|c|c|c|}
\hline \multirow[b]{2}{*}{ Radiologic and laboratory findings } & \multirow[b]{2}{*}{$\begin{array}{c}\text { All Patients } \\
323\end{array}$} & \multicolumn{3}{|c|}{ Disease severity group } & \multirow[t]{2}{*}{$p$ Value } & \multicolumn{2}{|c|}{ Clinical outcome } & \multirow[t]{2}{*}{$p$ Value } \\
\hline & & $\begin{array}{c}\text { Non-severe } \\
151\end{array}$ & $\begin{array}{c}\text { Severe } \\
146\end{array}$ & $\begin{array}{c}\text { Critical } \\
26\end{array}$ & & $\begin{array}{c}\text { Unfavorable } \\
63\end{array}$ & $\begin{array}{c}\text { Favorable } \\
260\end{array}$ & \\
\hline \multicolumn{9}{|l|}{ Radiologic findings } \\
\hline \multicolumn{9}{|l|}{ Abnormalities on chest CT } \\
\hline Bilateral GGO & $166 / 323(51.4)$ & $83 / 151(55)$ & $76 / 146(52.1)$ & $7 / 26(26.9)$ & 0.03 & 24/63(38.1) & $142 / 260(54.6)$ & 0.027 \\
\hline Crazy paving sign & $27 / 323(8.4)$ & $7 / 151(4.6)$ & $15 / 146(10.3)$ & $5 / 26(19.2)$ & 0.02 & 10/63(15.9) & $17 / 260(6.5)$ & 0.032 \\
\hline $\begin{array}{l}\text { Diffuse patchy ground glass and } \\
\text { air bronchogram }\end{array}$ & $25 / 323(7.7)$ & $11 / 151(7.3)$ & $11 / 146(7.5)$ & $3 / 26(11.5)$ & 0.693 & $9 / 63(14.3)$ & $16 / 260(6.2)$ & 0.04 \\
\hline $\begin{array}{l}\text { Bilateral pulmonary multiple } \\
\text { consideration and intralobular } \\
\text { interstitial thickening }\end{array}$ & $9 / 323(2.8)$ & $2 / 151(1.3)$ & $4 / 146(2.7)$ & $3 / 26(11.5)$ & 0.02 & $7 / 63(11.1)$ & $2 / 260(0.8)$ & $<0.001$ \\
\hline White blood cell count, $>10 \times 10^{9} / \mathrm{L}$ & $23 / 323(7.1)$ & $5 / 140(3.6)$ & $13 / 141(9.2)$ & $5 / 24(20.8)$ & 0.009 & $16 / 61(26.2)$ & $7 / 244(2.9)$ & $<0.001$ \\
\hline Neutrophil count, $>75 \times 10^{9} / \mathrm{L}$ & $100 / 323(31)$ & $39 / 140(27.9)$ & 40/141(28.4) & $21 / 24(87.5)$ & 0 & $43 / 61(70.5)$ & $57 / 244(23.4)$ & $<0.001$ \\
\hline Lymphocyte count, $<20 \times 10^{9} / \mathrm{L}$ & $181 / 323(56)$ & $72 / 140(51.4)$ & $87 / 141(61.7)$ & $22 / 24(91.7)$ & 0 & $51 / 61(83.6)$ & $130 / 244(53.3)$ & $<0.001$ \\
\hline Platelet count, $<100 \times 10^{9} / \mathrm{L}$ & $16 / 323(5)$ & $4 / 138(2.9)$ & $9 / 141(6.4)$ & $3 / 24(12.5)$ & 0.095 & $7 / 61(11.5)$ & $9 / 242(3.7)$ & 0.036 \\
\hline C-reactive protein $\mathrm{mg} /$ liter & & & & & & & & 0.001 \\
\hline$<3$ & $30 / 323(9.3)$ & $13 / 141(9.2)$ & 17/139(12.2) & $0 / 26(0)$ & 0.143 & $0 / 60(0)$ & $30 / 246(12.2)$ & \\
\hline$>3$ & $276 / 323(85.4)$ & $128 / 141(90.8)$ & $122 / 139(87.8)$ & $26 / 26(100)$ & 0.143 & $60 / 60(100)$ & $216 / 246(87.8)$ & \\
\hline Serum amyloid $A>10 \mathrm{mg} /$ liter & $35 / 323(10.8)$ & $14 / 136(10.3)$ & $21 / 133(15.8)$ & $0 / 23(0)$ & 0.06 & $1 / 55(1.8)$ & $34 / 237(14.3)$ & 0.006 \\
\hline $\begin{array}{l}\text { Hypersensitive troponin } \mathrm{l},>0.04 \\
\mathrm{pg} / \mathrm{mL}\end{array}$ & $68 / 323(21.1)$ & $21 / 100(21)$ & $41 / 123(33.3)$ & $6 / 21(28.6)$ & 0.144 & 19/49(38.7) & $49 / 195(25.1)$ & 0.084 \\
\hline Prothrombin time, $>14 \mathrm{~s}$ & $39 / 323(12.1)$ & $9 / 124(7.3)$ & $24 / 137(17.5)$ & $6 / 26(23.1)$ & 0.018 & $13 / 56(23.2)$ & 26/231(11.3) & 0.034 \\
\hline Creatine kinase-CMB, $\mathrm{U} / \mathrm{L}+$ & & & & & & & & 0.007 \\
\hline$<5$ & $49 / 323(15.2)$ & $14 / 41(34.1)$ & $33 / 47(70.2)$ & 2/11(18.2) & $<0.001$ & $5 / 22(22.7)$ & $44 / 77(57.1)$ & \\
\hline$>5$ & $50 / 323(15.5)$ & $27 / 41(65.9)$ & $14 / 47(29.8)$ & $9 / 11(81.8)$ & $<0.001$ & $17 / 22(77.3)$ & $33 / 77(42.9)$ & \\
\hline \multicolumn{9}{|l|}{ Lactate dehydrogenase, $\mathrm{U} / \mathrm{L}+$} \\
\hline$<120$ & $46 / 323(14.2)$ & $14 / 38(36.8)$ & $30 / 42(71.4)$ & $2 / 7(28.6)$ & 0.002 & $4 / 15(26.7)$ & $42 / 72(58.3)$ & 0.044 \\
\hline$>250$ & $22 / 323(6.8)$ & $12 / 38(31.6)$ & $6 / 42(14.3)$ & $4 / 7(57.1)$ & 0.028 & $9 / 15(60)$ & $13 / 72(18.1)$ & 0.002 \\
\hline
\end{tabular}

Alanine aminotransferase, $U / L$ 
Hu et al. 22

\begin{tabular}{|c|c|c|c|c|c|c|c|c|}
\hline$<7$ & $44 / 323(13.6)$ & $14 / 145(9.7)$ & $30 / 143(21)$ & $0 / 25(0)$ & 0.002 & $3 / 62(4.8)$ & $41 / 251(16.3)$ & 0.023 \\
\hline$>40$ & $58 / 323(18)$ & $26 / 145(17.9)$ & $24 / 143(16.8)$ & $8 / 25(32)$ & 0.189 & $19 / 62(30.6)$ & $39 / 251(15.5)$ & 0.01 \\
\hline \multicolumn{9}{|l|}{ artate aminotransferase, $\mathrm{U} / \mathrm{L}$} \\
\hline$<13$ & $49 / 323(15.2)$ & $14 / 145(9.7)$ & $33 / 144(22.9)$ & $2 / 25(8)$ & 0.004 & $4 / 62(6.5)$ & 45/252(17.9) & 0.03 \\
\hline$>35$ & $89 / 323(27.6)$ & $33 / 145(22.8)$ & $40 / 144(27.8)$ & $16 / 25(64)$ & $<0.001$ & $32 / 62(51.6)$ & $57 / 252(22.6)$ & $<0.001$ \\
\hline urea nitrogen, >8 mmol/L & $72 / 323(22.3)$ & $18 / 145(12.4)$ & $46 / 142(32.4)$ & $8 / 25(32)$ & $<0.001$ & $22 / 61(36.1)$ & $50 / 251(19.9)$ & 0.012 \\
\hline \multicolumn{9}{|l|}{ atinine, $\mu \mathrm{mol} / \mathrm{L}$} \\
\hline$<88$ & 269/323(83.3) & $128 / 145(88.3)$ & $120 / 144(83.3)$ & $21 / 25(84)$ & 0.452 & $46 / 62(74.2)$ & $223 / 252(88.5)$ & 0.007 \\
\hline$>144$ & $7 / 323(2.2)$ & $2 / 145(1.4)$ & $4 / 144(2.8)$ & $1 / 25(4)$ & 0.321 & $4 / 62(6.5)$ & $3 / 252(1.2)$ & 0.03 \\
\hline \multicolumn{9}{|l|}{ cose, $\mathrm{mmol} / \mathrm{L}$} \\
\hline$<3.9$ & $43 / 323(13.3)$ & $14 / 137(10.2)$ & 29/143(20.3) & $0 / 21(0)$ & 0.007 & $2 / 59(3.4)$ & $41 / 242(16.9)$ & 0.006 \\
\hline 5.1 & $108 / 323(33.4)$ & $38 / 137(27.7)$ & $52 / 143(36.4)$ & $18 / 21(85.7)$ & $<0.001$ & $38 / 59(64.4)$ & $70 / 242(28.9)$ & $<0.001$ \\
\hline & & & & & & & & $<0.001$ \\
\hline sitive & $186 / 323(57.6)$ & $69 / 151(45.7)$ & $95 / 146(65.1)$ & $22 / 26(84.6)$ & $<0.001$ & $50 / 63(79.4)$ & $136 / 260(52.3)$ & \\
\hline gative & $137 / 323(42.4)$ & $82 / 151(54.3)$ & $51 / 146(34.9)$ & 4/26(15.4) & $<0.001$ & $13 / 63(20.6)$ & $124 / 260(47.7)$ & \\
\hline
\end{tabular}

†Data were missing for creatine kinase in $226(69.5 \%)$ for lactate dehydrogenase in $238(73.2 \%)$ 


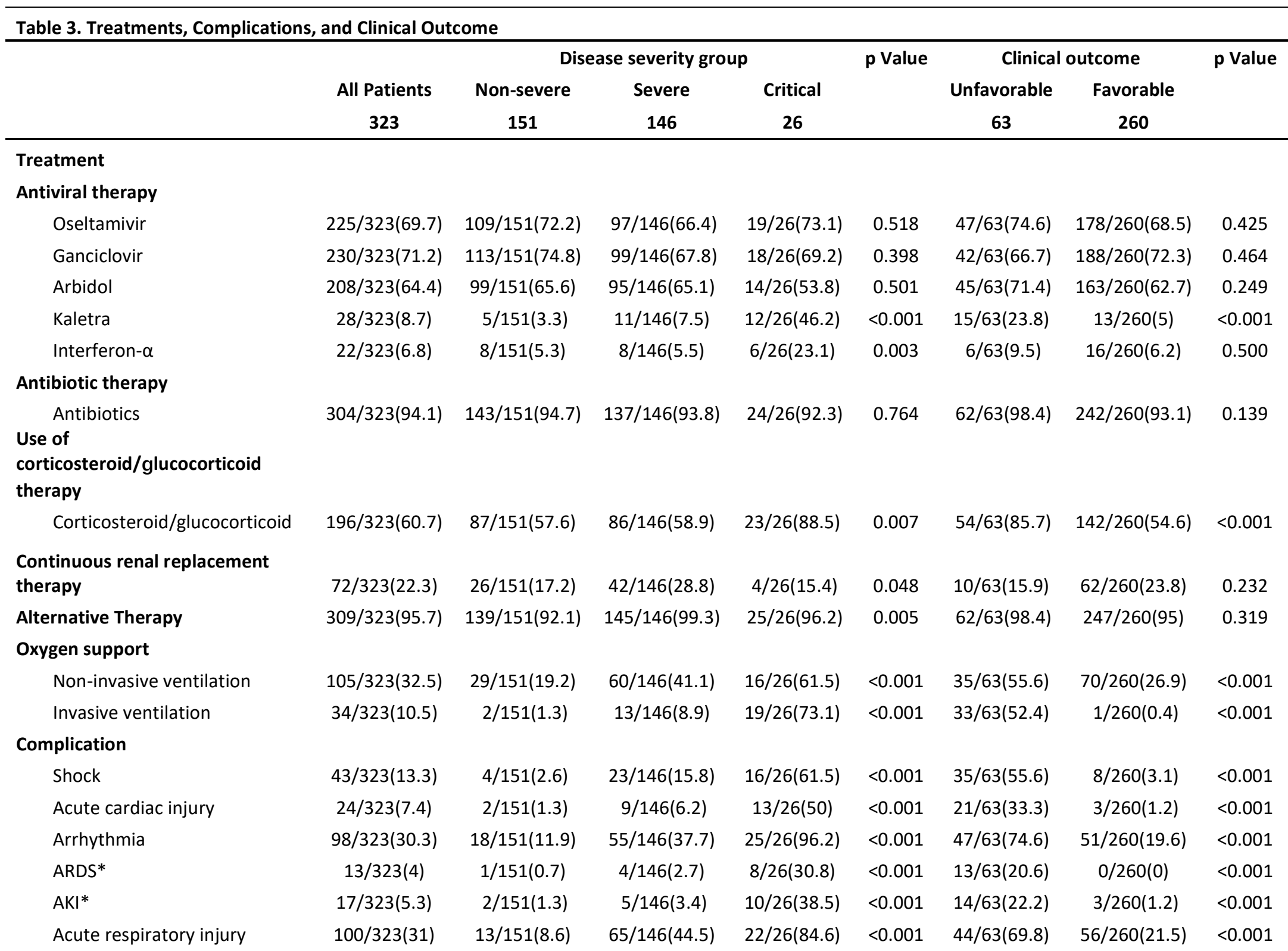




\begin{tabular}{ccccccccc} 
Septic shock & $19 / 323(5.9)$ & $0 / 151(0)$ & $2 / 146(1.4)$ & $17 / 26(65.4)$ & $<0.001$ & $19 / 63(30.2)$ & $0 / 260(0)$ & $<0.001$ \\
Secondary infection & $9 / 323(2.8)$ & $1 / 151(0.7)$ & $4 / 146(2.7)$ & $4 / 26(15.4)$ & 0.002 & $9 / 63(14.3)$ & $0 / 260(0)$ & $<0.001$ \\
\hline *ARDS, Acute respiratory distress syndrome; AKI, Acute kidney injury
\end{tabular}


Figure 1

A

$1007 \quad 131 / 151$

Unfavorable

medRxiv preprint doi: https://doi.ory/10.1101/2020.03.25.20037721; this $35^{6}$ version posted March 30.2020 The copyright holder for this preprint (which was not certified by $\beta$ er review) is the author/funder, who has granted medRxiv a license

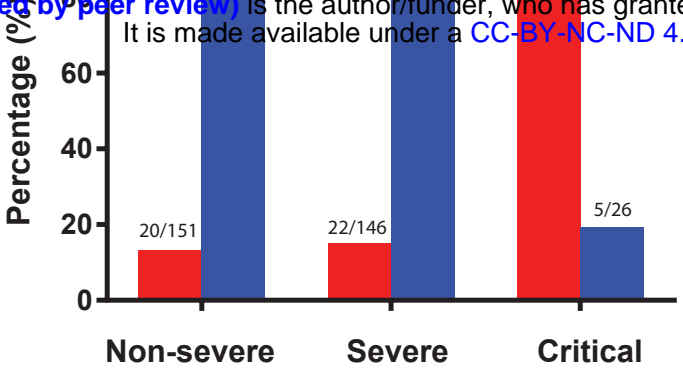

B

Hypnotics

Unfavorable

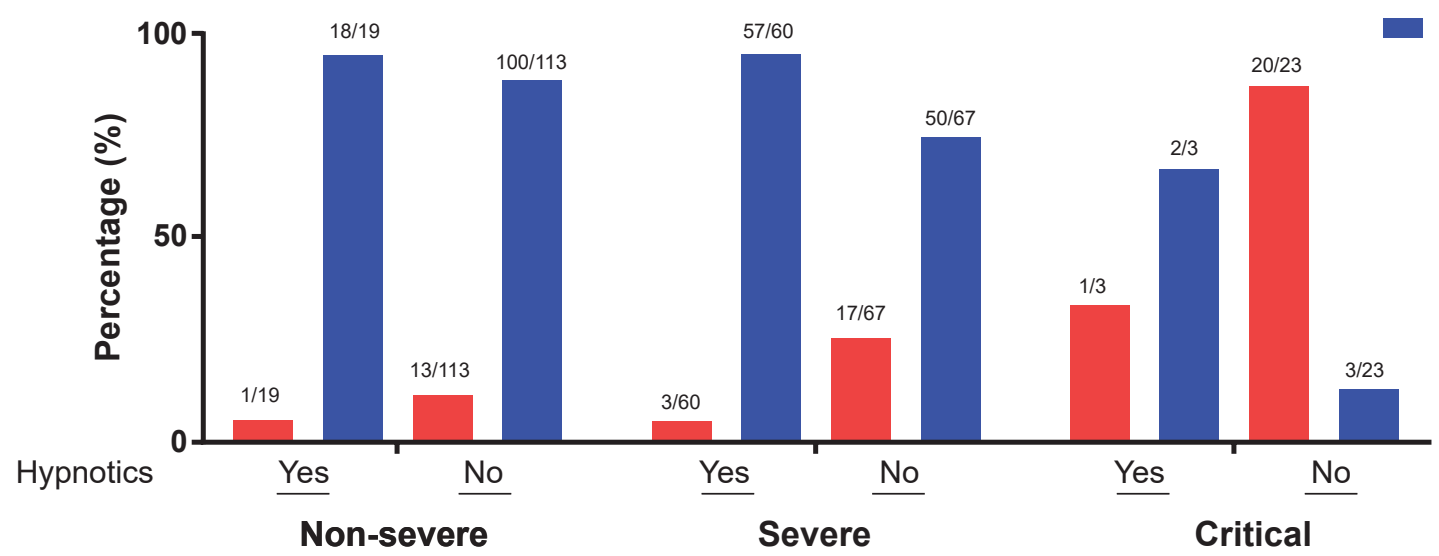

C

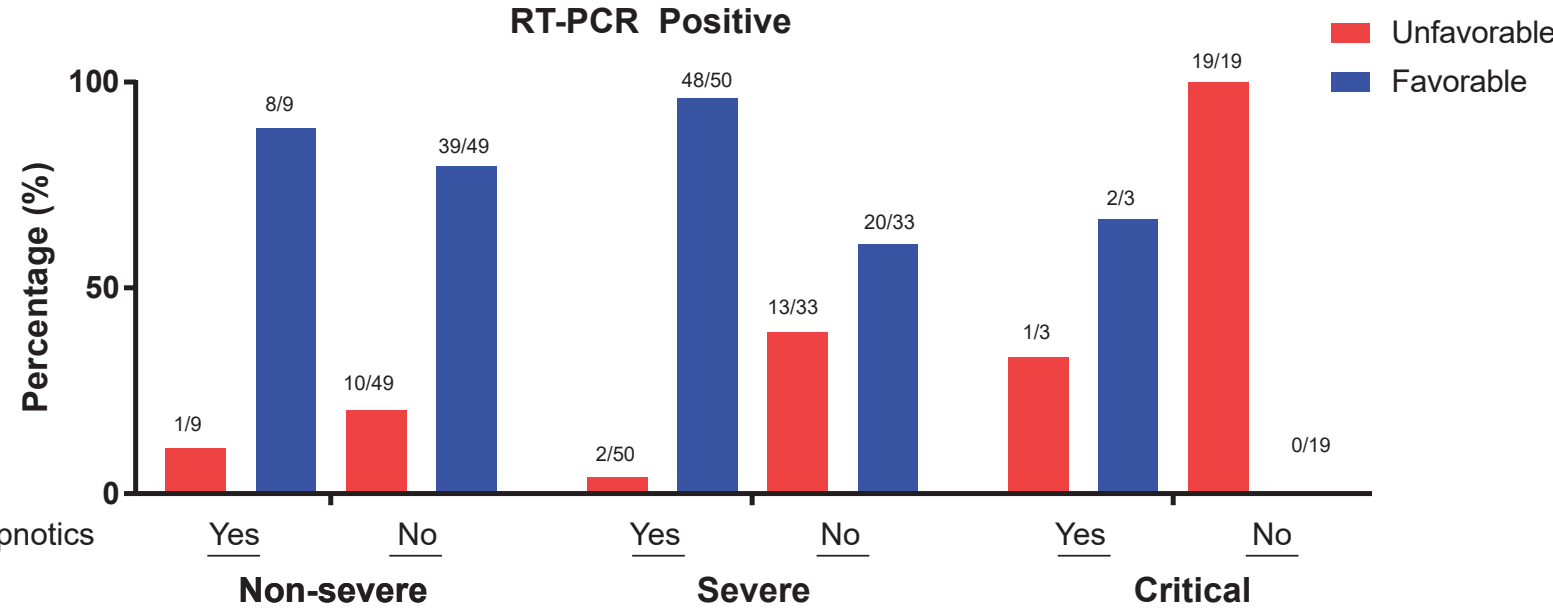

D

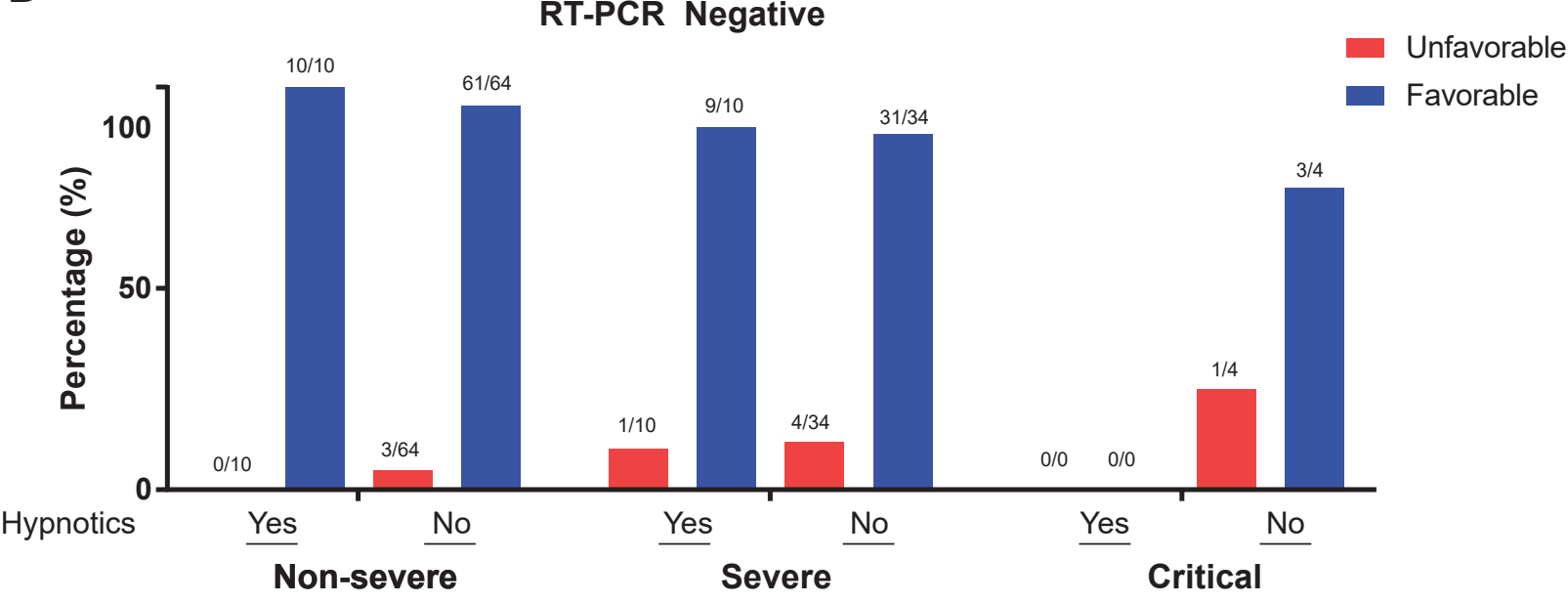




\section{Figure 2}

medRxiv preprint doi: https://doi.org/10.1101/2020.03.25.20037721; this version posted March 30, 2020. The copyright holder for this preprint (which was not certified by peer review) is the author/funder, who has granted medRxiv a license to display the preprint in perpetuity.

A It is made available under a CC-BY-NC-ND 4.0 International license.

B

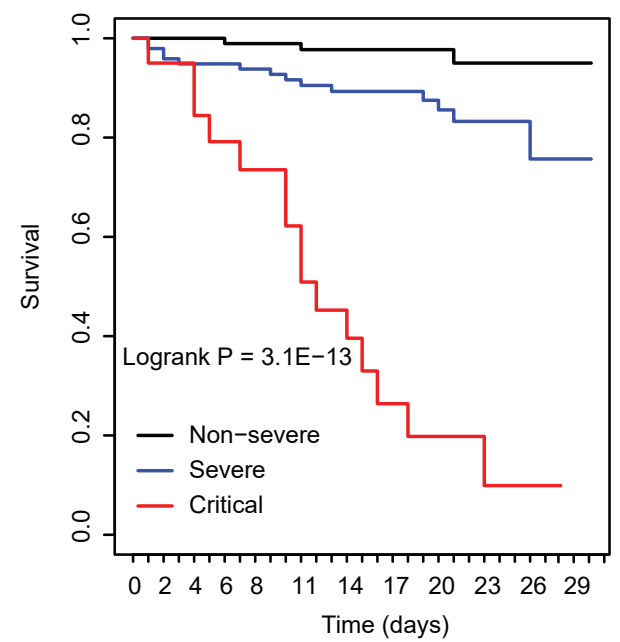

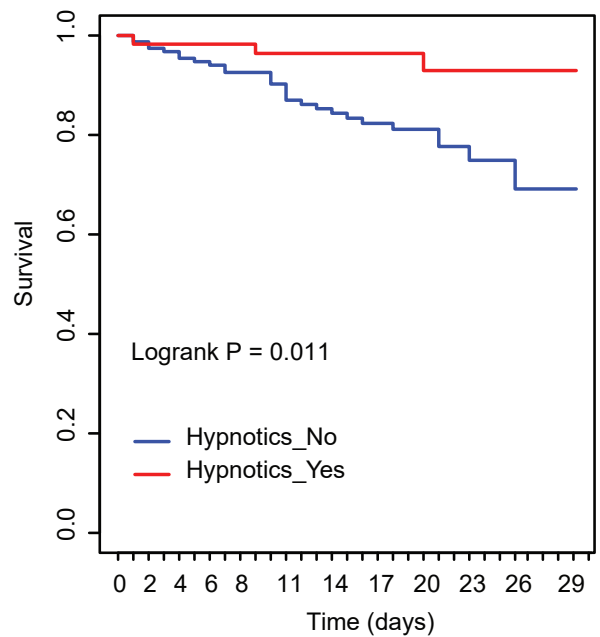

OR(95\% Cl)

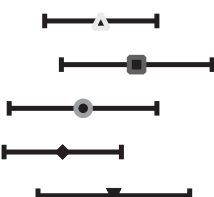

$5.929(2.299-15.290) \quad<0.001$

$10.853(3.040-38.748) \quad<0.001$

$4.388(1.261-15.271) \quad 0.02$

$3.109(1.155-8.373) \quad 0.025$

$7.390(2.056-26.569) \quad 0.002$

$0.082(0.025-0.274) \quad<0.001$

$3.464(1.18-10.166) \quad 0.001$

$3.546(1.626-7.733) \quad<0.001$
C

B

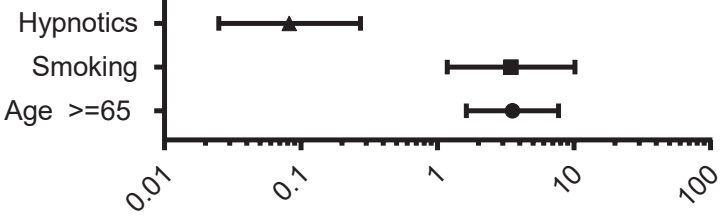

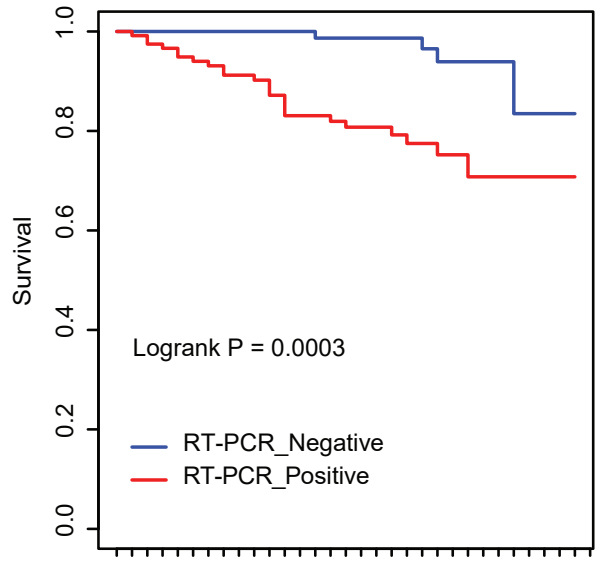

$\begin{array}{llllllllllll}0 & 2 & 4 & 6 & 8 & 11 & 14 & 17 & 20 & 23 & 26 & 29\end{array}$ Time (days) 


\section{Figure legends:}

Figure 1. Clinical outcomes for the three disease severity groups.

(A) Overall clinical outcomes of patients in the non-severe, severe, and critical disease groups. The percentages are calculated by the number of each outcome group (Unfavorable or Favorable) divided by the total number of patients in each group. (B) Clinical outcomes of patients in the non-severe, severe, and critical disease groups who were either administered hypnotics or not. (C) Clinical outcomes of RT-PCR-positive patients in the non-severe, severe, and critical disease groups who were either administered hypnotics or not. D) Clinical outcomes of RT-PCR-negative patients in the non-severe, severe, and critical disease groups who were either administered hypnotics or not. The percentages are calculated by the number of each outcome group (Unfavorable or Favorable) divided by the total number at each diagnosis status with either using (Yes) or not using (No) hypnotics.

Figure 2. Multivariate regression and Kaplan-Meier curves of survival analysis.

(A) Factors showing significantly independent association with clinical outcome. Odds ratio, 95\%CI, and $P$ values are derived from logistic regression modelling. (B) Kaplan-Meier curve demonstrating survival of COVID-19 patients by disease severity group: non-severe, severe, and critical. (C) Kaplan-Meier curve demonstrating survival of COVID-19 patients by the usage of hypnotics. (D) Kaplan-Meier curve demonstrating survival of COVID-19 patients by RT-PCR results. $P$ values for survival analysis are derived by the log-rank test. 


\section{Supplementary Figure S1}
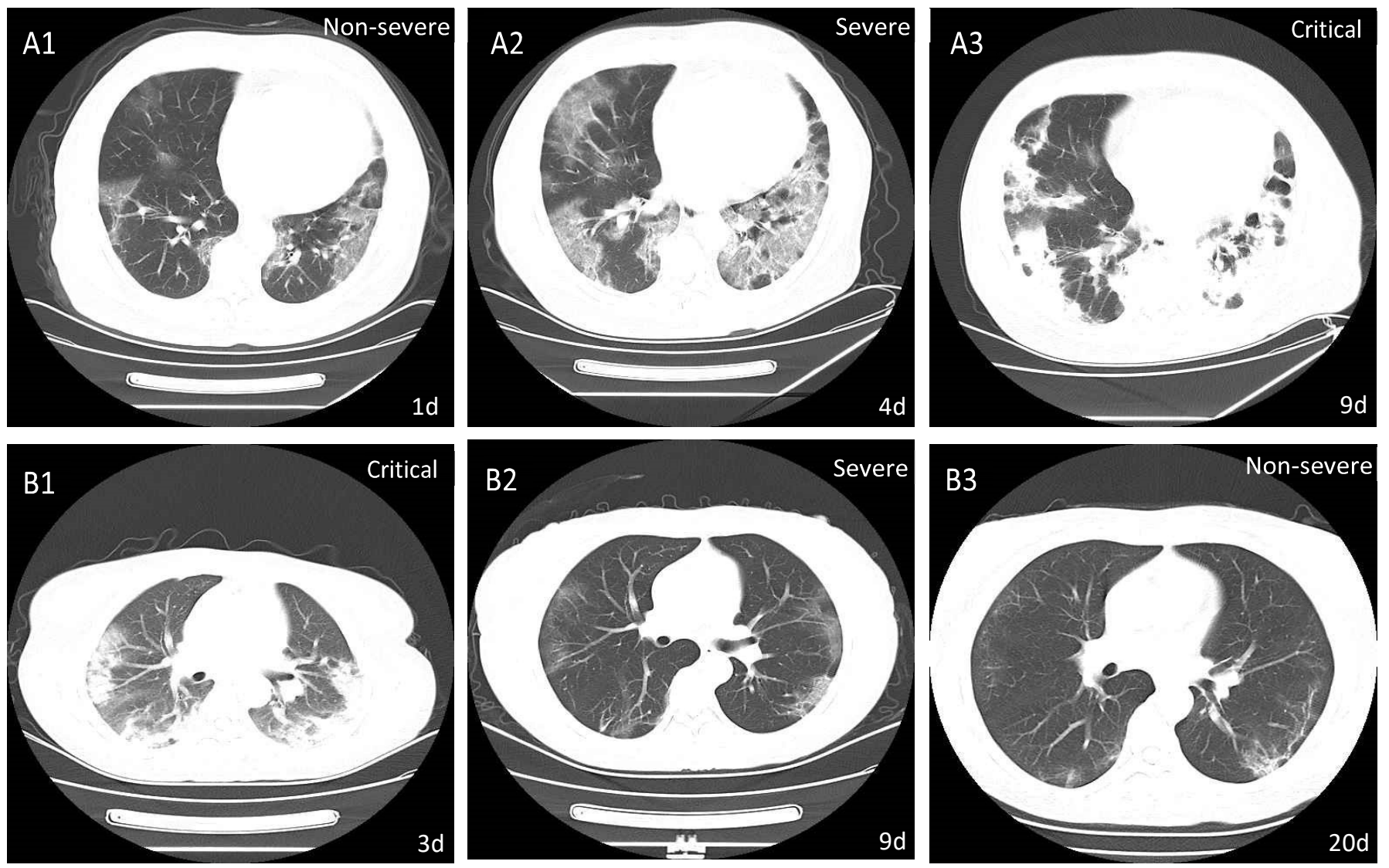

Figure S1. Representative dynamic changes in chest computer tomography (CT) scans from two patients with COVID-19. A1-A3, CT images of a 70year-old male patient, who progressed from the non-severe to critical disease group, and died. A1 (day 1), A2 (day 4), A3 (day 9): below the pleura are scattered shadows of frosted glass, large sheet diffuse paving stones in both lungs, and extensive consolidation of both lungs with thickening of interlobular stroma repetitively. B1-B3, CT images of a 44-year-old female patient, who progressed from the critical to non-severe disease group. B1 (day 3) exhibiting extensive consolidation of both lungs; B2 (day 9) exhibiting frosted hyaline change and paving stone signs. B3 (day 20) showing significant resolution of ground-glass opacities and subpleural cord changes. 


\section{Supplementary Figure S2}

A

medRxiv preprint doi: https://doi.org/10.1101/2020.03.25.20037721; this version posted March 30, 2020. The copyright holder for this preprint (which was not certified by peer review) is the author/funder, wh has granted medRxiv a license to display the preprint in perpetuity.

Kaletra

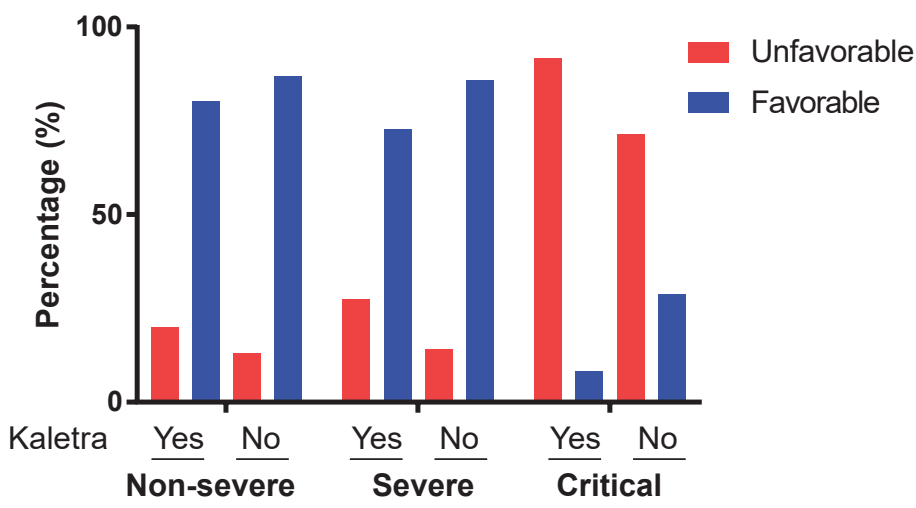

C

\section{Invasive ventilation}

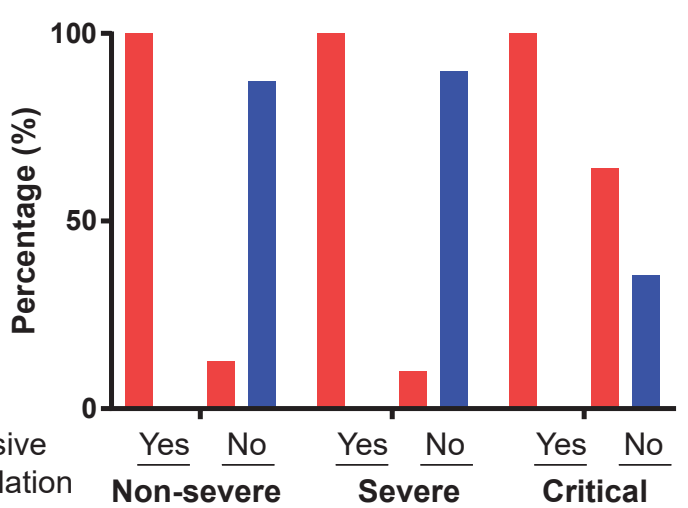

\section{Non-invasive ventilation}

Unfavorable

Favorable

Interferon

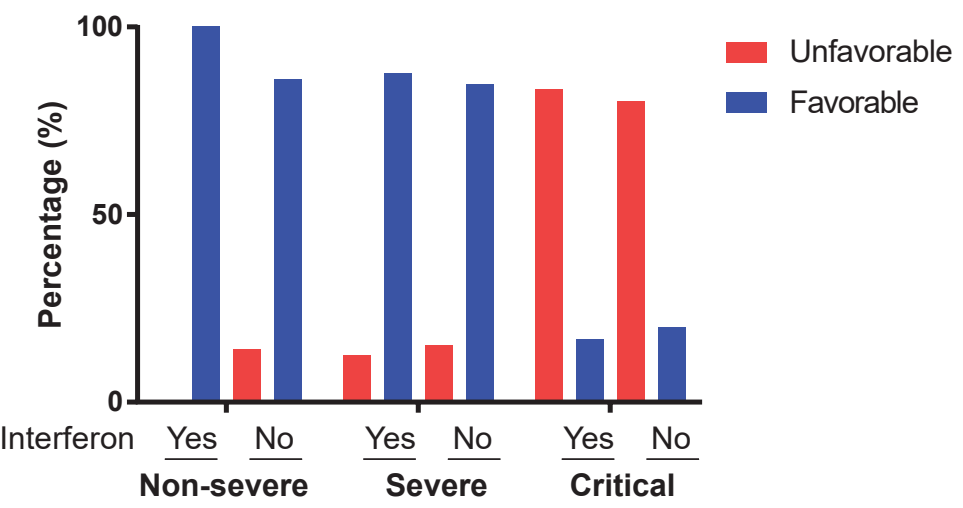

$\mathrm{D}$

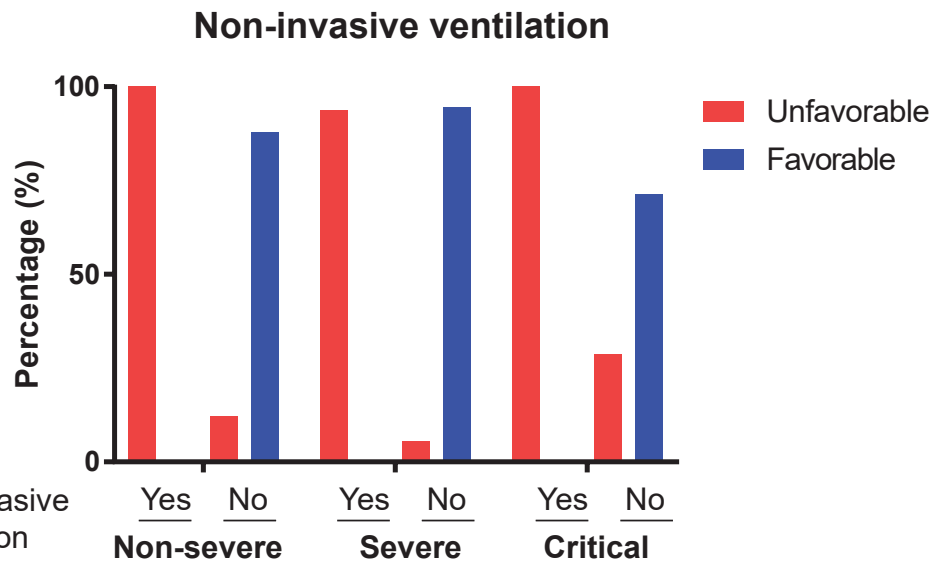

Figure S2: The association of different treatments with clinical outcome in three diagnostic status. The association of clinical outcome with three diagnosis status: Non-severe, Severe, and Critical under the treatment A) Kaletra, B) Interferon, C) Invasive ventilation, D) Non-invasive ventilation. The percentages are calculated by the number of each outcome group (Unfavorable or Favorable) divided by the total number at each diagnosis status with (Yes) using or not (No) using a treatment. 


\section{Supplementary Table S1}

\begin{tabular}{|c|c|c|c|c|c|c|c|c|}
\hline \multicolumn{9}{|c|}{ Supplementary Table S1. Radiographic and laboratory findings of 323 patients with COVID-19 } \\
\hline \multirow{3}{*}{ Radiologic and laboratory findings } & \multirow{3}{*}{$\begin{array}{l}\text { All Patients } \\
323\end{array}$} & \multicolumn{3}{|c|}{ Disease severity group } & \multirow[t]{3}{*}{ p Value } & \multicolumn{2}{|c|}{ Clinical outcome } & \multirow[t]{3}{*}{ p Value } \\
\hline & & Non-severe & Severe & Critical & & Unfavorable & Favorable & \\
\hline & & 151 & 146 & 26 & & 63 & 260 & \\
\hline \multicolumn{9}{|l|}{ Radiologic findings } \\
\hline \multicolumn{9}{|l|}{ Abnormalities on chest CT } \\
\hline No GGO & $9 / 323(2.8)$ & $4 / 151(2.6)$ & $4 / 146(2.7)$ & $1 / 26(3.8)$ & 0.768 & $0 / 63(0)$ & $9 / 260(3.5)$ & 0.214 \\
\hline Local GGO & $17 / 323(5.3)$ & 11/151(7.3) & $6 / 146(4.1)$ & $0 / 26(0)$ & 0.317 & $1 / 63(1.6)$ & $16 / 260(6.2)$ & 0.211 \\
\hline Bilateral GGO & $166 / 323(51.4)$ & $83 / 151(55)$ & $76 / 146(52.1)$ & $7 / 26(26.9)$ & 0.030 & $24 / 63(38.1)$ & $142 / 260(54.6)$ & 0.027 \\
\hline $\begin{array}{l}\text { Combination of patchy ground glass } \\
\text { opacity and pulmonary consolidation }\end{array}$ & $61 / 323(18.9)$ & $28 / 151(18.5)$ & 29/146(19.9) & $4 / 26(15.4)$ & 0.930 & $8 / 63(12.7)$ & $53 / 260(20.4)$ & 0.223 \\
\hline Crazy paving sign & $27 / 323(8.4)$ & $7 / 151(4.6)$ & $15 / 146(10.3)$ & $5 / 26(19.2)$ & 0.020 & 10/63(15.9) & $17 / 260(6.5)$ & 0.032 \\
\hline $\begin{array}{l}\text { Diffuse patchy ground glass and air } \\
\text { bronchogram }\end{array}$ & $25 / 323(7.7)$ & 11/151(7.3) & $11 / 146(7.5)$ & $3 / 26(11.5)$ & 0.693 & $9 / 63(14.3)$ & $16 / 260(6.2)$ & 0.040 \\
\hline $\begin{array}{l}\text { Bilateral pulmonary multiple } \\
\text { consideration and intralobular interstitial } \\
\text { thickening }\end{array}$ & $9 / 323(2.8)$ & $2 / 151(1.3)$ & $4 / 146(2.7)$ & $3 / 26(11.5)$ & 0.020 & $7 / 63(11.1)$ & $2 / 260(0.8)$ & $<0.001$ \\
\hline \multicolumn{9}{|l|}{ Laboratory findings } \\
\hline $\mathrm{PH}^{*}$ & & & & & 0.036 & & & 0.478 \\
\hline$<7.35$ & $1 / 323(0.3)$ & $0 / 17(0)$ & $0 / 33(0)$ & $1 / 11(9.1)$ & 0.180 & $1 / 19(5.3)$ & $0 / 42(0)$ & 0.311 \\
\hline
\end{tabular}




\begin{tabular}{|c|c|c|c|c|c|c|c|c|}
\hline 7.35-7.45 & $20 / 323(6.2)$ & $9 / 17(52.9)$ & $7 / 33(21.2)$ & $4 / 11(36.4)$ & 0.071 & $6 / 19(31.6)$ & $14 / 42(33.3)$ & 1.000 \\
\hline$>7.45$ & $40 / 323(12.4)$ & $8 / 17(47.1)$ & $26 / 33(78.8)$ & $6 / 11(54.5)$ & 0.062 & $12 / 19(63.2)$ & $28 / 42(66.7)$ & 1.000 \\
\hline Lactate, $\mathrm{mmol} / \mathrm{L} *$ & & & & & 0.290 & & & 0.533 \\
\hline$<0.5$ & $1 / 323(0.3)$ & $0 / 15(0)$ & $1 / 33(3)$ & $0 / 11(0)$ & 1.000 & $0 / 18(0)$ & $1 / 41(2.4)$ & 1.000 \\
\hline $0.5-1.6$ & $44 / 323(13.6)$ & $13 / 15(86.7)$ & 25/33(75.8) & $6 / 11(54.5)$ & 0.176 & $12 / 18(66.7)$ & $32 / 41(78)$ & 0.549 \\
\hline$>1.6$ & $14 / 323(4.3)$ & $2 / 15(13.3)$ & $7 / 33(21.2)$ & $5 / 11(45.5)$ & 0.169 & 6/18(33.3) & $8 / 41(19.5)$ & 0.414 \\
\hline $\mathrm{PaO2}, \mathrm{mmHg}$ * & & & & & 0.943 & & & 0.593 \\
\hline$<80$ & $36 / 323(11.1)$ & $11 / 17(64.7)$ & 19/33(57.6) & $6 / 11(54.5)$ & 0.882 & $11 / 19(57.9)$ & $25 / 42(59.5)$ & 1.000 \\
\hline $80-100$ & $12 / 323(3.7)$ & $3 / 17(17.6)$ & $6 / 33(18.2)$ & $3 / 11(27.3)$ & 0.825 & $5 / 19(26.3)$ & $7 / 42(16.7)$ & 0.489 \\
\hline$>100$ & $13 / 323(4)$ & $3 / 17(17.6)$ & $8 / 33(24.2)$ & $2 / 11(18.2)$ & 0.915 & $3 / 19(15.8)$ & $10 / 42(23.8)$ & 0.737 \\
\hline $\mathrm{PaCO}, \mathrm{mmHg}$ * & & & & & 0.006 & & & 1.000 \\
\hline$<35$ & $36 / 323(11.1)$ & $10 / 17(58.8)$ & $24 / 33(72.7)$ & $2 / 11(18.2)$ & 0.006 & $11 / 19(57.9)$ & $25 / 42(59.5)$ & 1.000 \\
\hline $35-45$ & $25 / 323(7.7)$ & $7 / 17(41.2)$ & 9/33(27.3) & 9/11(81.8) & 0.006 & $8 / 19(42.1)$ & $17 / 42(40.5)$ & 1.000 \\
\hline $\mathrm{PaO2} / \mathrm{Fio2}$ * & & & & & 0.301 & & & 0.422 \\
\hline$<400$ & 48/323(14.9) & $11 / 16(68.8)$ & $28 / 32(87.5)$ & 9/11(81.8) & 0.292 & $16 / 18(88.9)$ & $32 / 41(78)$ & 0.476 \\
\hline $400-500$ & $6 / 323(1.9)$ & $2 / 16(12.5)$ & $2 / 32(6.2)$ & $2 / 11(18.2)$ & 0.522 & 2/18(11.1) & $4 / 41(9.8)$ & 1.000 \\
\hline$>500$ & $5 / 323(1.5)$ & $3 / 16(18.8)$ & $2 / 32(6.2)$ & $0 / 11(0)$ & 0.295 & $0 / 18(0)$ & $5 / 41(12.2)$ & 0.310 \\
\hline White blood cell count, $\times 10^{9} / \mathrm{L}$ & & & & & 0.041 & & & $<0.001$ \\
\hline$<4$ & $90 / 323(27.9)$ & 46/140(32.9) & 39/141(27.7) & $5 / 24(20.8)$ & 0.444 & $14 / 61(23)$ & 76/244(31.1) & 0.272 \\
\hline $4-10$ & 192/323(59.4) & 89/140(63.6) & $89 / 141(63.1)$ & $14 / 24(58.3)$ & 0.885 & $31 / 61(50.8)$ & $161 / 244(66)$ & 0.041 \\
\hline$>10$ & $23 / 323(7.1)$ & $5 / 140(3.6)$ & 13/141(9.2) & $5 / 24(20.8)$ & 0.009 & $16 / 61(26.2)$ & $7 / 244(2.9)$ & $<0.001$ \\
\hline
\end{tabular}


Neutrophil count, $\times 10^{9} / \mathrm{L}$

$$
<40
$$

40-75

$>75$

Lymphocyte count, $\times 10^{9} / \mathrm{L}$

$<20$

20-50

$>50$

Monocyte count, $\times 10^{9} / \mathrm{L}$

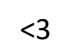

3-10

$>10$

Platelet count, $\times 10^{9} / \mathrm{L}$

$<100$

100-300

$>300$

C-reactive protein level $\mathrm{mg} /$ liter

$<3$

$>3$

SAA $\mathrm{mg} /$ liter

$<10$

\begin{tabular}{|c|c|c|c|c|c|c|c|}
\hline & & & & 0.000 & & & $<0.001$ \\
\hline $70 / 323(21.7)$ & $28 / 140(20)$ & 42/141(29.8) & $0 / 24(0)$ & 0.001 & $8 / 61(13.1)$ & $62 / 244(25.4)$ & 0.061 \\
\hline $135 / 323(41.8)$ & $73 / 140(52.1)$ & $59 / 141(41.8)$ & $3 / 24(12.5)$ & 0.001 & $10 / 61(16.4)$ & $125 / 244(51.2)$ & $<0.001$ \\
\hline $100 / 323(31)$ & 39/140(27.9) & 40/141(28.4) & $21 / 24(87.5)$ & $<0.001$ & $43 / 61(70.5)$ & $57 / 244(23.4)$ & $<0.001$ \\
\hline & & & & 0.002 & & & $<0.001$ \\
\hline $181 / 323(56)$ & 72/140(51.4) & 87/141(61.7) & 22/24(91.7) & 0.000 & $51 / 61(83.6)$ & $130 / 244(53.3)$ & $<0.001$ \\
\hline $120 / 323(37.2)$ & $66 / 140(47.1)$ & $52 / 141(36.9)$ & $2 / 24(8.3)$ & 0.001 & $10 / 61(16.4)$ & $110 / 244(45.1)$ & $<0.001$ \\
\hline $4 / 323(1.2)$ & $2 / 140(1.4)$ & 2/141(1.4) & $0 / 24(0)$ & 1.000 & $0 / 61(0)$ & $4 / 244(1.6)$ & 0.587 \\
\hline & & & & 0.305 & & & 0.127 \\
\hline $103 / 323(31.9)$ & 44/138(31.9) & $54 / 141(38.3)$ & $5 / 24(20.8)$ & 0.195 & $27 / 61(44.3)$ & $76 / 242(31.4)$ & 0.081 \\
\hline $159 / 323(49.2)$ & $72 / 138(52.2)$ & 70/141(49.6) & $17 / 24(70.8)$ & 0.157 & $29 / 61(47.5)$ & $130 / 242(53.7)$ & 0.471 \\
\hline $41 / 323(12.7)$ & 22/138(15.9) & 17/141(12.1) & $2 / 24(8.3)$ & 0.576 & $5 / 61(8.2)$ & $36 / 242(14.9)$ & 0.212 \\
\hline & & & & 0.154 & & & 0.014 \\
\hline $16 / 323(5)$ & $4 / 138(2.9)$ & $9 / 141(6.4)$ & $3 / 24(12.5)$ & 0.095 & $7 / 61(11.5)$ & $9 / 242(3.7)$ & 0.036 \\
\hline $232 / 323(71.8)$ & $112 / 138(81.2)$ & $102 / 141(72.3)$ & $18 / 24(75)$ & 0.217 & $48 / 61(78.7)$ & $184 / 242(76)$ & 0.788 \\
\hline $55 / 323(17)$ & 22/138(15.9) & $30 / 141(21.3)$ & $3 / 24(12.5)$ & 0.433 & $6 / 61(9.8)$ & $49 / 242(20.2)$ & 0.089 \\
\hline & & & & 0.143 & & & 0.001 \\
\hline $30 / 323(9.3)$ & $13 / 141(9.2)$ & $17 / 139(12.2)$ & $0 / 26(0)$ & 0.143 & $0 / 60(0)$ & $30 / 246(12.2)$ & \\
\hline $276 / 323(85.4)$ & $128 / 141(90.8)$ & $122 / 139(87.8)$ & $26 / 26(100)$ & 0.143 & $60 / 60(100)$ & $216 / 246(87.8)$ & \\
\hline & & & & 0.061 & & & 0.006 \\
\hline $35 / 323(10.8)$ & $14 / 136(10.3)$ & 21/133(15.8) & $0 / 23(0)$ & 0.060 & $1 / 55(1.8)$ & $34 / 237(14.3)$ & \\
\hline
\end{tabular}


$>10$

Prothrombin time, s

$<9$

$>14$

Activated partial thromboplastin time, s

D-dimer mg/liter

$<0.5$

$>0.5$

Hypersensitive troponin I, pg/mL

$<0.04$

$>0.04$

Creatine kinase-CMB, $\mathrm{U} / \mathrm{L}+$

$<5$

$>5$

Lactate dehydrogenase, U/L †

$<120$

$120-250$

$>250$

Alanine aminotransferase, $U / L$

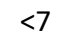

7-40

\begin{tabular}{|c|c|c|c|c|c|c|c|}
\hline $256 / 323(79.3)$ & 121/136(89) & $112 / 133(84.2)$ & 23/23(100) & 0.071 & $54 / 55(98.2)$ & $202 / 237(85.2)$ & \\
\hline & & & & 0.713 & & & 0.044 \\
\hline $18 / 323(5.6)$ & $6 / 124(4.8)$ & $10 / 137(7.3)$ & $2 / 26(7.7)$ & 0.663 & $1 / 56(1.8)$ & $17 / 231(7.4)$ & 0.214 \\
\hline 39/323(12.1) & $9 / 124(7.3)$ & $24 / 137(17.5)$ & $6 / 26(23.1)$ & 0.018 & $13 / 56(23.2)$ & $26 / 231(11.3)$ & 0.034 \\
\hline $30.7(0-2406)$ & $33(0.014-57)$ & $34.3(0-59.3)$ & $26.9(1-2406)$ & 0.001 & $34.2(1.193-57)$ & $30.4(0-2406)$ & 0.098 \\
\hline & & & & 0.002 & & & 0.137 \\
\hline 160/323(49.5) & 83/120(69.2) & 68/138(49.3) & 9/21(42.9) & 0.002 & 24/52(46.2) & 136/228(59.6) & \\
\hline 119/323(36.8) & 37/120(30.8) & 70/138(50.7) & 12/21(57.1) & 0.003 & 27/52(51.9) & $92 / 228(40.4)$ & \\
\hline & & & & 0.124 & & & 0.084 \\
\hline $176 / 323(54.5)$ & 79/100(79) & 82/123(66.7) & 15/21(71.4) & 0.086 & 30/49(61.2) & 146/195(74.9) & \\
\hline 68/323(21.1) & 21/100(21) & 41/123(33.3) & 6/21(28.6) & 0.144 & 19/49(38.7) & 49/195(25.1) & \\
\hline & & & & $<0.001$ & & & 0.007 \\
\hline 49/323(15.2) & 14/41(34.1) & 33/47(70.2) & 2/11(18.2) & $<0.001$ & $5 / 22(22.7)$ & 44/77(57.1) & \\
\hline 50/323(15.5) & 27/41(65.9) & 14/47(29.8) & 9/11(81.8) & $<0.001$ & 17/22(77.3) & 33/77(42.9) & \\
\hline & & & & 0.007 & & & 0.004 \\
\hline 46/323(14.2) & $14 / 38(36.8)$ & 30/42(71.4) & 2/7(28.6) & 0.002 & 4/15(26.7) & 42/72(58.3) & 0.044 \\
\hline 19/323(5.9) & 12/38(31.6) & 6/42(14.3) & 1/7(14.3) & 0.159 & 2/15(13.3) & 17/72(23.6) & 0.506 \\
\hline $22 / 323(6.8)$ & 12/38(31.6) & 6/42(14.3) & 4/7(57.1) & 0.028 & $9 / 15(60)$ & 13/72(18.1) & 0.002 \\
\hline & & & & 0.005 & & & 0.004 \\
\hline 44/323(13.6) & 14/145(9.7) & $30 / 143(21)$ & $0 / 25(0)$ & 0.002 & $3 / 62(4.8)$ & 41/251(16.3) & 0.023 \\
\hline $211 / 323(65.3)$ & $105 / 145(72.4)$ & $89 / 143(62.2)$ & $17 / 25(68)$ & 0.183 & $40 / 62(64.5)$ & 171/251(68.1) & \\
\hline
\end{tabular}




\begin{tabular}{|c|c|c|c|c|c|c|c|c|}
\hline$>40$ & $58 / 323(18)$ & 26/145(17.9) & $24 / 143(16.8)$ & $8 / 25(32)$ & 0.189 & $19 / 62(30.6)$ & $39 / 251(15.5)$ & 0.010 \\
\hline Aspartate aminotransferase, $\mathrm{U} / \mathrm{L}$ & & & & & $<0.001$ & & & $<0.001$ \\
\hline$<13$ & $49 / 323(15.2)$ & $14 / 145(9.7)$ & $33 / 144(22.9)$ & $2 / 25(8)$ & 0.004 & $4 / 62(6.5)$ & $45 / 252(17.9)$ & 0.030 \\
\hline $13-35$ & $176 / 323(54.5)$ & $98 / 145(67.6)$ & $71 / 144(49.3)$ & $7 / 25(28)$ & $<0.001$ & $26 / 62(41.9)$ & $150 / 252(59.5)$ & 0.018 \\
\hline$>35$ & $89 / 323(27.6)$ & $33 / 145(22.8)$ & $40 / 144(27.8)$ & $16 / 25(64)$ & $<0.001$ & $32 / 62(51.6)$ & $57 / 252(22.6)$ & $<0.001$ \\
\hline Total bilirubin, $\mathrm{mmol} / \mathrm{L}$ & & & & & 0.076 & & & 0.152 \\
\hline$<5$ & $21 / 323(6.5)$ & $10 / 145(6.9)$ & $11 / 144(7.6)$ & $0 / 25(0)$ & 0.511 & $1 / 62(1.6)$ & $20 / 252(7.9)$ & 0.090 \\
\hline $5-22$ & $248 / 323(76.8)$ & $121 / 145(83.4)$ & $109 / 144(75.7)$ & $18 / 25(72)$ & 0.181 & $50 / 62(80.6)$ & $198 / 252(78.6)$ & 0.853 \\
\hline$>22$ & $45 / 323(13.9)$ & $14 / 145(9.7)$ & $24 / 144(16.7)$ & $7 / 25(28)$ & 0.030 & $11 / 62(17.7)$ & $34 / 252(13.5)$ & 0.514 \\
\hline Blood urea nitrogen, $\mathrm{mmol} / \mathrm{L}$ & & & & & 0.001 & & & 0.018 \\
\hline$<3$ & $51 / 323(15.8)$ & 26/145(17.9) & $21 / 142(14.8)$ & $4 / 25(16)$ & 0.776 & $6 / 61(9.8)$ & $45 / 251(17.9)$ & 0.180 \\
\hline 3-8 & $189 / 323(58.5)$ & $101 / 145(69.7)$ & $75 / 142(52.8)$ & $13 / 25(52)$ & 0.009 & $33 / 61(54.1)$ & $156 / 251(62.2)$ & 0.313 \\
\hline$>8$ & $72 / 323(22.3)$ & 18/145(12.4) & $46 / 142(32.4)$ & $8 / 25(32)$ & $<0.001$ & $22 / 61(36.1)$ & 50/251(19.9) & 0.012 \\
\hline Creatinine, $\mu \mathrm{mol} / \mathrm{L}$ & & & & & 0.587 & & & 0.007 \\
\hline$<88$ & $269 / 323(83.3)$ & $128 / 145(88.3)$ & $120 / 144(83.3)$ & $21 / 25(84)$ & 0.452 & $46 / 62(74.2)$ & $223 / 252(88.5)$ & 0.007 \\
\hline $88-144$ & $38 / 323(11.8)$ & $15 / 145(10.3)$ & 20/144(13.9) & $3 / 25(12)$ & 0.623 & $12 / 62(19.4)$ & $26 / 252(10.3)$ & 0.082 \\
\hline$>144$ & $7 / 323(2.2)$ & $2 / 145(1.4)$ & $4 / 144(2.8)$ & $1 / 25(4)$ & 0.321 & $4 / 62(6.5)$ & $3 / 252(1.2)$ & 0.030 \\
\hline Procalcitonin, $\mathrm{ng} / \mathrm{mL}$ & & & & & 0.018 & & & 0.624 \\
\hline$<0.1$ & $198 / 323(61.3)$ & $98 / 117(83.8)$ & $88 / 123(71.5)$ & $12 / 20(60)$ & 0.018 & $37 / 51(72.5)$ & $161 / 209(77)$ & \\
\hline$>0.1$ & $62 / 323(19.2)$ & 19/117(16.2) & $35 / 123(28.5)$ & $8 / 20(40)$ & 0.018 & $14 / 51(27.5)$ & $48 / 209(23)$ & \\
\hline Glucose, $\mathrm{mmol} / \mathrm{L}$ & & & & & $<0.001$ & & & $<0.001$ \\
\hline
\end{tabular}




\begin{tabular}{|c|c|c|c|c|c|c|c|c|}
\hline$<3.9$ & $43 / 323(13.3)$ & $14 / 137(10.2)$ & 29/143(20.3) & $0 / 21(0)$ & 0.007 & $2 / 59(3.4)$ & 41/242(16.9) & 0.006 \\
\hline $3.9-6.1$ & $150 / 323(46.4)$ & $85 / 137(62)$ & $62 / 143(43.4)$ & $3 / 21(14.3)$ & $<0.001$ & $19 / 59(32.2)$ & $131 / 242(54.1)$ & 0.004 \\
\hline$>6.1$ & $108 / 323(33.4)$ & $38 / 137(27.7)$ & $52 / 143(36.4)$ & $18 / 21(85.7)$ & $<0.001$ & $38 / 59(64.4)$ & $70 / 242(28.9)$ & $<0.001$ \\
\hline Potassium, $\mathrm{mmol} / \mathrm{L}$ & & & & & 0.022 & & & 0.581 \\
\hline$<3.5$ & $73 / 323(22.6)$ & 27/143(18.9) & 42/137(30.7) & 4/21(19) & 0.063 & $15 / 58(25.9)$ & $58 / 243(23.9)$ & 0.882 \\
\hline $3.5-5.5$ & 225/323(69.7) & 116/143(81.1) & $93 / 137(67.9)$ & $16 / 21(76.2)$ & 0.037 & $42 / 58(72.4)$ & $183 / 243(75.3)$ & 0.774 \\
\hline$>5.5$ & $3 / 323(0.9)$ & $0 / 143(0)$ & $2 / 137(1.5)$ & $1 / 21(4.8)$ & 0.057 & $1 / 58(1.7)$ & $2 / 243(0.8)$ & 0.475 \\
\hline RT-PCR & & & & & $<0.001$ & & & $<0.001$ \\
\hline Positive & $186 / 323(57.6)$ & $69 / 151(45.7)$ & $95 / 146(65.1)$ & $22 / 26(84.6)$ & $<0.001$ & $50 / 63(79.4)$ & $136 / 260(52.3)$ & \\
\hline Negative & $137 / 323(42.4)$ & $82 / 151(54.3)$ & $51 / 146(34.9)$ & $4 / 26(15.4)$ & $<0.001$ & 13/63(20.6) & $124 / 260(47.7)$ & \\
\hline
\end{tabular}

*Data were missing for $\mathrm{PH}$ in 262(81.1\%), for lactate in 266(81.8\%), for $\mathrm{PaO2}$ in 262(81.1\%), for PaCO2 in 265(82.5\%), for PaO2:FiO2 in 264(81.7\%)

tData were missing for creatine kinase in $224(69.3 \%)$ for lactate dehydrogenase in $236(73.1 \%)$

\section{Supplementary Table S2}

\begin{tabular}{|c|c|c|c|c|c|}
\hline \multirow{2}{*}{ Variables } & & \multicolumn{4}{|c|}{ Univariate Analysis } \\
\hline & & Odds Ratio & & $\% \mathrm{Cl}$ & $p$ \\
\hline Age & $\geq 65$ & 15.274 & 2.016 & 115.741 & 0.001 \\
\hline Smoking & Yes & 2.118 & 1.002 & 4.474 & 0.049 \\
\hline
\end{tabular}


BMI

Hypnotics

Dyspnea

Diabetes

Cardiovascular and cerebrovascular diseases

Malignancy

Serum amyloid $A, \mathrm{mg} /$ liter

Procalcitonin, $\mathrm{ng} / \mathrm{mL}$

Hypersensitive troponin I, pg/mL

Creatine kinase $\mathrm{CMB}, \mathrm{U} / \mathrm{L}$

Lactate dehydrogenase, $\mathrm{U} / \mathrm{L}$

Alanine aminotransferase, U/L

Aspartate aminotransferase, U/L

Blood urea nitrogen, $\mathrm{mmol} / \mathrm{L}$

Creatinine, $\mu \mathrm{mol} / \mathrm{L}$

Glucose, $\mathrm{mmol} / \mathrm{L}$

$\begin{array}{lllll}<7 & 0.313 & 0.092 & 1.061 & 0.014 \\ >40 & 2.083 & 1.09 & 3.979 & 0.002\end{array}$

$\begin{array}{lllll}\geq 30 & 3.604 & 1.154 & 11.256 & 0.009 \\ \text { Yes } & 0.199 & 0.076 & 0.519 & <0.001 \\ \text { Yes } & 3.316 & 1.107 & 9.93 & 0.032 \\ \text { Yes } & 3.578 & 1.839 & 6.963 & <0.001 \\ \text { Yes } & 2.154 & 1.043 & 4.449 & 0.038 \\ \text { Yes } & 6.45 & 1.054 & 39.456 & 0.044 \\ >10 & 9.356 & 1.253 & 69.852 & 0.029 \\ \geq 0.1 & 0.252 & 0.074 & 0.852 & 0.027 \\ >0.04 & 3.562 & 1.028 & 12.338 & 0.045 \\ \geq 5 & 4.43 & 1.481 & 13.247 & 0.008 \\ >250 & 5.885 & 1.082 & 32.013 & 0.003\end{array}$

$<13$

$\begin{array}{lllll}<13 & 0.525 & 0.174 & 1.584 & 0.024 \\ >35 & 3.239 & 1.776 & 5.906 & <0.001 \\ >8 & 2.08 & 1.112 & 3.892 & 0.006 \\ <88 & 0.447 & 0.21 & 0.95 & 0.003\end{array}$


White blood cell count, $\times 10^{9} / \mathrm{L}$

Neutrophil count, $\times 10^{9} / \mathrm{L}$

Platelet count, $\times 10^{9} / \mathrm{L}$

PCR at Diagnosis

Disease severity on admission

Bilateral GGO

\section{Crazy paving sign}

Diffuse patchy ground glass and air bronchogram

Multiple Bilateral pulmonary multiple consideration

and intralobular interstitial thickening

$\begin{array}{lllll}>6.1 & 3.743 & 2.008 & 6.975 & <0.001 \\ >10 & 11.871 & 4.51 & 31.245 & <0.001 \\ >75 & 9.43 & 4.427 & 20.084 & <0.001 \\ \geq 150 & 2.981 & 1.056 & 8.415 & 0.008 \\ \text { positive } & 2.862 & 1.472 & 5.565 & 0.00194 \\ & & & & \\ \text { Severe } & 1.162 & 0.605 & 2.234 & <0.001 \\ \text { Critical } & 27.51 & 9.315 & 81.241 & <0.001 \\ \text { Yes } & 0.511 & 0.291 & 0.899 & 0.020 \\ \text { Yes } & 2.697 & 1.169 & 6.22 & 0.020 \\ \text { Yes } & 2.542 & 1.067 & 6.056 & 0.035 \\ \text { Yes } & 16.112 & 3.261 & 79.602 & <0.001\end{array}$

